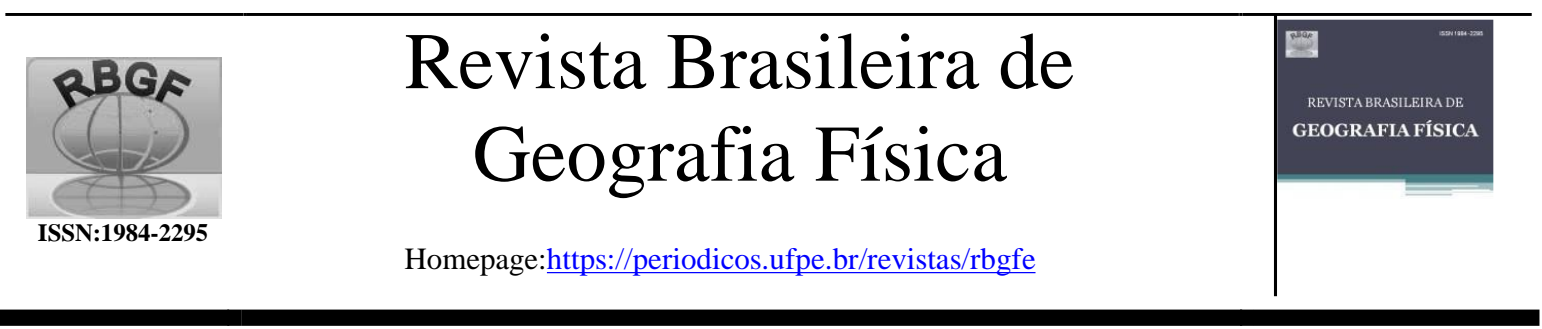

\title{
O uso dos dados lidar para a compreensão da dinâmica de escoamento e acúmulo de águas em Recife - PE
}

\author{
Alessandra de Santana Lima ${ }^{1}$; Camila Gardenea de Almeida Bandim²; Gabriel Antonio Silva \\ Soares $^{3}$; Juliana Patrícia Fernandes Guedes Barros ${ }^{4}$; Josiclêda Domiciano Galvíncio ${ }^{5}$
}

\begin{abstract}
${ }^{1 a ̀} 4$ Graduandos do curso de Licenciatura em Geografia do Departamento de Ciências Geográficas da Universidade Federal de Pernambuco (UFPE), Recife/PE - Brasil; (alessandra.santanal@ufpe.br; camila.bandim@ufpe.br; gabriel.antonios@ufpe.br; juliana.guedesbarros@ufpe.br) 5 Professora Associado do Departamento de Ciências Geográficas da Universida de Federal de Perna mbuco (UFPE), Progra ma de Pós-Graduação em Desenvolvimento e Meio Ambiente-PRODEMA. Recife/PE - Brasil; (josicleda.galvincio@ufpe.br)
\end{abstract}

Artigo recebido em 10/06/2020 e aceito em 20/10/2021

\begin{abstract}
R E S U M O
Os grandes aglomerados urbanos desencadeiam profundas problemáticas de natureza hidroclimática, resultantes principalmente das formas de uso e ocupação do solo. Os padrões hídricos, tais como escoamento e acúmulo de fluxo, são afetados diretamente pelo efeito de impermeabilização do solo decorrente das construções humanas e quando esta estrutura urbana é somada aos eventos climáticos extremos, culminam na ocorrência periódic a de inundações. Diante deste contexto, o presente estudo tem como objetivo compreender e identificar os danos hidrológicos decorrentes da concentração urbana, sobre a dinâmica natural do escoamento, a fim de investigar os fatores que provocam estas inundações nas determinadas regiões. A área de estudo do presente trabalho é representada por folhas de amostra gem do sensor LiDAR das Regiões político administrativas IV e VI do município do Recife, Pernambuco. Para subsidiar a análise proposta, os modelos digita is de elevação do projeto Perna mbuco 3D, provenientes do sensor LiDAR, foram processados em a mbiente SIG, e a partir destes dados de alta resolução espacial foi possível a na lisar detalhadamente as variá veis que propiciam o escoamento superficial e acúmulo de fluxo nas áreas em estudo. Os resultados obtidos para as áreas de a mostragem, foram analisados e comparados com as políticas públicas de drenagem urbana e planejamento territorial vigentes, a valiando a relação entre as redes de macro e microdrena gem, com a ocorrência de inundações no meio urbano. Palavras-chave: Geoprocessamento. Sensoria mento remoto. Urbanização. Inundação urbana. Escoamento superficial.
\end{abstract}

\section{The use of lidar data for the understanding of water flow and accumulation dynamics in the Recife - PE}

\begin{abstract}
A B S T R A C T
Large urban agglomerations result in huge problems of hydroclimatic nature, resulting mainly from the forms of land use and occupation. Water patterns, such as runoff and flow accumulation, are directly affected by the waterproofing effect from human constructions, and when added to the extreme weather events, they culminate in a periodic occurrence of urban floods. The study area of the present work is represented by the LiDAR sensor sampling sheets from the administrative political Regions IV and VI of the municipality of Recife, in Perna mbuco. Given this context, the present study aims to understand and identify the hydrological da mage caused by the urban concentration on the natural dyna mics of runoff, to investigate the factors that cause these floods in that specific region. To subsidize the proposed analysis, the digital elevation models of the Pernambuco 3D project, from the LiDAR sensor, were processed in a GIS environment, and from these high spatial resolution data it was possible to analyze in detail the variables that propitiate surface runoff and flow accumulation in the areas under study. The results obtained for the sampling areas were analyzed and compared with the urban drainage and territorial planning public policies in force, evaluating the relationship between the macro and micro draina ge networks, with the occurrence of floods in the urban environment.
\end{abstract}

Keywords: Geoprocessing. remote sensing. urbanization. urban flood. surface runoff. 


\section{Introdução}

$\mathrm{O}$ intenso crescimento populacional ocorrido nas últimas décadas, têm impactado de forma direta nas dinâmicas hídricas naturais dos grandes centros urbanos. No Brasil, em 1940, a concentraçãourbanaera de $31 \%$ da população total e, em 2010 já era superior a $85 \%$, segundo Stamm (2013). Esse crescimento desenfreado da população nas áreas urbanas, acompanhado de um mal planejamento ambiental, altera os padrões de comportamentohidrológico, tais como os cursos da água, e resulta no aumento do número de áreas impermeáveis, findando em um maior acúmulo de água na superfície.

Esse cenário de acúmulo de águas em superfície é comum em centros urbanos, pois as águas advindas das chuvas esbarram constantemente em construções humanas, e não conseguem percorrer até o seu destino natural. Tais construções, dificultam ainda nainfiltraçãode água no solo, o que acaba por tornar os solos impermeáveis, ou seja, esses solos perdem a capacidade de absorçãoda água, em decorrência da presença de elementos não-naturais neste espaço, resultando também em acúmulo indevido de água na superfície. Além dessas questões decorrentes da urbanização, os problemas no sistema de drenagem das grandes cidades, é um outro fator que propicia o acúmulo de águana superfície; a esse acúmulo de águas em determinados locais por deficiência no sistema de drenagem, se dá o nome de alagamento (Tucci, 1997) e na literatura internacional inundações urbanas, (Brown, 2007; Fewtrell, 2010; Gallegos, 2009; Mason, 2006; Ozdemir, 2013; Sampson, 2012; Tsubaki, 2010).

Situado às margens do Oceano Atlântico e construído sobre aterro. o município litorâneo do Recife, que se localiza a apenas 4 metros acima do nível oceano, vem lidando com questões relacionadas ocorrência de enchentes, inundações e alagamentos há séculos: sendo a primeira registrada, no ano de 1632, segundo matéria publicada pelo Diário de Pernambuco (2016), descrita como "a perda de muitas casas e vivandeiros estabelecidos às margens do (Rio) Capibaribe". Hoje, quase quatro séculos após o primeiro registro da ocorrência de um evento ex tremo de origem climática-hídrica nos territórios recifenses, a população local continua a lidar com os impactos dos fortes índices pluviométricos sobre as estruturas urbanas não planejadas desenvolvidas na capital pernambucana.

As características naturais da cidade do Recife, como os altos índices de precipitação distribuídas ao longo do ano, e a presença de corpos hídricos espalhados por todo o território, inclusive em áreas urbanizadas: propiciam uma frequência na ocorrência de tais fenômenos hidrológicos. Somadas à um mal planejamento urbano do uso e ocupação das áreas das bacias, tais eventos são intensificados, tanto em ocorrências, quanto em magnitude; o que resulta em catástrofes urbanas, ocorridas periodicamente, e nunca solucionadas (Oliveira, 2011).

Como forma de aperfeiçoamento no planejamento e gerenciamento dos sistemas de drenagem e controle de alagamentos e inundações nos centros urbanos, são utilizados modelos hidrológicos, capazes de prever as consequências de diferentes formas de uso e ocupação das áreas da bacia, bem como solucionar problemas de drenagem da água superficial. A utilização desses modelos, pode subsidiar meios que resultem em um melhor uso desses espaços e reduzam problemas relacionados à hidrografia nas áreas urbanizadas. Além dos modelos hidrológicos, as técnicas de geoprocessamento também podem ser usadas na identificação de padrões hídricos a partir do reconhecimento do relevo, e na solução de problemas relacionados a urbanização das áreas das bacias hidrográficas. Rodrigues (2003), define geoprocessamento como um conjunto de tecnologias de coleta, tratamento, manipulação e representação de informações espaciais voltado para um objetivo específico, que no caso, seria solucionar as consequências das catástrofes hidrológicas sobre os residentes dos centros urbanos.

$$
\text { Uma das tecnologias de }
$$
geoprocessamento, utilizadas para o reconhecimento do relevo e a identificação dos problemas hídricos decorrentes da urbanização, é o sensoriamento remoto. Novo (2010), define sensoriamento remoto como utilização conjunta de sensores, equipamentos para processamento de dados, equipamentos de transmissão de dados colocados a bordo de aeronaves espaçonaves, ou outras plataformas, com o objetivo de estudar eventos, fenômenos e processos que ocorrem na superfície do planeta Terra, a partir do registro e da análise das interações entre a radiação 
eletromagnética e as substâncias que a compõem em suas mais diversas manifestações.

O uso de tecnologias de sensoriamento remoto tem sido bastante frequentes em estudos de bacias hidrográficas, Lima et al., (2021), Galvincio e Luz (2021), França et al., (2019), Miranda et al., (2018), Brito et al., 2017) e de drenagem urbana, com o sensor lidar mais recentes estudos tem sido desenvolvido para caracterização fisiográfica de detalhe de bacias hidrográficas, Soares e Galvincio (2020), Bandim e Galvincio (2021).

Para o desenvolvimento deste estudo, buscou-se identificar espaços onde em decorrência das características do relevo e da urbanização, ocorressem com frequência alagamentos em Recife, utilizando ferramentas de geoprocessamento. Destacou-se duas das seis Regiões Político-administrativa do Recife. Segundo a Lei $\mathrm{N}^{\circ} 16.293 / 97$, que dispõe sobre as regiões político-administrativas do município do Recife, as RPAs são sedes municipais onde se encontram unidades administrativas da cidade e de onde será articulado um melhor planejamento para suas microrregiões.

Diante desse contexto, o presente trabalho tem como objetivo analisar a intrínseca relação entre uso e ocupação solo e alterações ao ciclo hídrico e consequências da urbanização sobre os padrões de escoamento e acúmulo de água na superfície.

O enfoque será no manejo de águas pluviais e as problemáticas ocasionadas pela falta de infraestrutura de drenagem urbana, a fim de entender a relação desses fatores com os dados obtidos, quanto à topografia e suscetibilidade a alagamentos. Pode-se indagar como estão relacionados e/ou condicionados os processosentre alteração do ciclo hidrológico e alagamentos? Como características geomorfológicas influenciam neste processo?

\section{Material e métodos}

\section{Área de Estudo}

Esse estudo foi desenvolvido a partir das análises topográfica, urbana e regime de escoamento de duas RPAs da capital pernambucana, o Recife. O município, está situado nas seguintes coordenadas geográficas: latitude $8^{\circ}$ $3^{\prime} 28.22^{\prime \prime}$ S e longitude $34^{\circ} 52^{\prime} 58.43^{\prime \prime} \mathrm{w}$, de acordo com as coordenadas presentes no Google Earth; em uma altitude de 4 metros acima do nível mar e possuindo um território de $217 \mathrm{~km} 2$. Inserido em sua própria mesorregião, a Metropolitana do Recife, o município é dividido em seis regiões políticos-administrativas, onde se encontram distribuídos um total de 94 de bairros. No Recife atualmente, segundo estimativas do IBGE residem 1637834 habitantes, pouco mais de 100 mil habitantes a mais do que no último censo, o de 2010 , onde foram registrados 1537704 residentes na capital; ainda segundo o IBGE, o Recife possui uma densidade demográfica de aproximadamente 7.371 habitantes $/ \mathrm{km}^{2}$, o que leva a prefeitura a diagnosticar a cidade, como completamente urbanizada. Ocupando uma posição central no litoral do nordeste do Brasil, o município encontrase numa posição privilegiada, o que facilita transações comerciais e concede à capital o rótulo de metrópole.

Dentre as RPAs do Recife, as escolhidas para a realização deste estudo foram as RPAs $04 \mathrm{e}$ 06, Figura 1. Para maior detalhamento e observação minuciosa das questões tratadas neste estudo, foram delimitadas cinco quadrículas Lidar de amostragem de cada RPA, totalizando dez quadrículas de amostragem, com base na distribuição espacial delas na área de estudo. Sendo as quadrículas da RPA 04: 81_31-00, 81_60-05, 80_99-05, 80_09-00 e 80_49-00. E, as da RPA 06: 80_94-05, 90_25-00, 80_82-05, 90_01-05 e 80_51-00. Todas as quadrículas em questão correspondem a uma área de $4 \mathrm{~km}$, cada, localizadas na intersecção entre os bairros ou inteiramente inseridas. As quadrículas lidar foram delimitadas previamente, da região políticoadministrativa 4 e 6 do Recife, que compreendem os bairros Cordeiro, Ilha do Retiro, Iputinga, Madalena, Prado, Torre,Zumbi, Engenhodo Meio, Torrões, Caxangá, Cidade Universitária, Várzea, Boa Viagem, Brasília Teimosa, Imbiribeira, Ipsep, Pina, Ibura, Jordão e Cohab. 

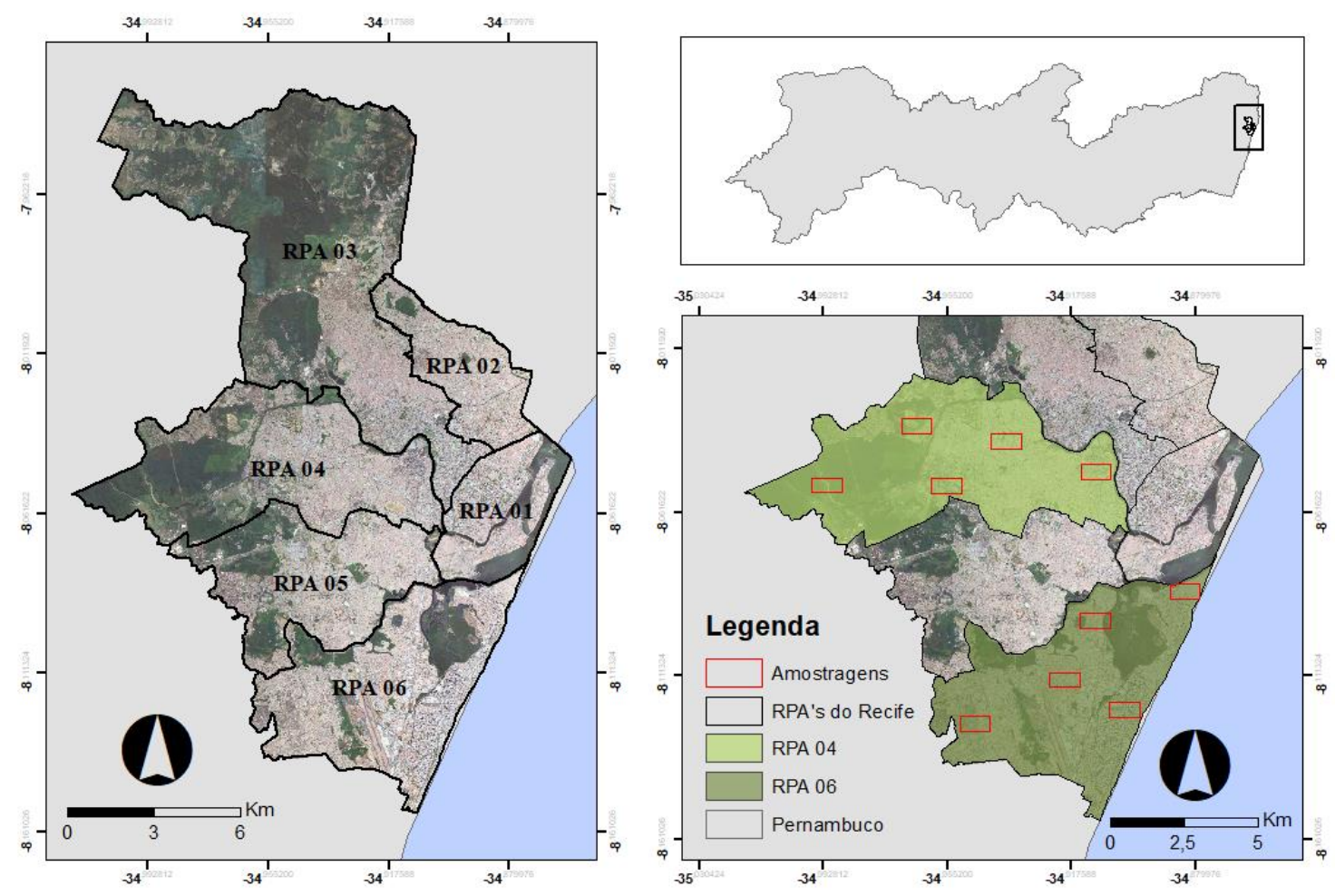

Figura 1: Localização das quadrículas em estudo inseridas na Região político-administrativa do recife.

\section{Procedimentos metodológicos}

Para uma análise detalhada das características topográficas das áreas da quadrícula, foram desenvolvidos modelos de elevaçãodigital (MDE) no QT Modeler, licenciado pelo Laboratório de Sensoriamento Remoto e Geoprocessamento-SERGEO, a fim de visualizar as diferenças de altitude no terreno e como esse fator implica nos padrões de escoamento e acúmulo de água nas áreas analisadas.

O principal dado utilizado neste estudo foi a nuvem de pontos e as imagens do sensor lidar disponibilizados pela Secretaria de Meio Ambiente, que por sua vez, pertence a prefeitura do Recife. O LIDAR (Light Detection and Ranging), é um sensor remoto que usa o sistema de varredura a laser e é utilizado nos processos de mapeamento de áreas, para representação de terrenos e das elevações nele contidas. A obtenção dos dados se dá a partir da emissão de um laser direcionado à área escolhida, e através do retorno desta energia emitida, é possível captar os dados da área. Essa alternativa de mapeamento se apresenta como uma forma rápida e eficiente na coleta de informações relativas à altura dos terrenos, com o intuito de responder às necessidades de análise, atualização e monitoramento das consequências de determinados usos da terra, seja no âmbito ambiental ou para demais necessidade que possam ser atendidas com o uso de modelos digitais ou imagens de lasers (Lins, 2018)

Após a obtenção desses dados, eles foram processados em softwares, no Quick Terrain Modeler, pode-se obter os modelos digital de elevação (MDE) e o modelo acima do nível da superfície (doinglês: Above Ground Level - AGL), e como o ArcMaps 9.3, licenciado pelo SERGEO, utilizando a ferramenta hydrology, foram obtidos $o$ mapa de localização da quadrícula no mapa dos bairros do Recife, e os padrões de escoamento nas áreas da quadrícula.

Já o Quick Terrain Modeler (QT Modeler), se trata de um software utilizado para a Visualização de nuvem de pontos e terreno em 3D. Projetado para o uso com LIDAR, mas flexivel o suficiente para acomodar outras fontes de dados 3D. O Quick Terrain Modeler fornece uma experiência de software fácil de usar que permite o processamento e o desenvolvimento de modelos analisar dados mais rapidamente e exportar uma variedade de produtos. E o ArcMap, é um aplicativo do ArcGIS voltado para o desenvolvimento e a análise de mapas, de modo a 
resolver questões geográficas, e para a auxiliar na produção cartográfica.

Esses modelos foram exportados em formato LAS Dataset, a fim de efetuar o processamento dos dados na ferramenta hydrology do ARCGIS.

$\mathrm{Na}$ ferramenta hydrology foram obtidos os padrões de escoamento superficial e acúmulo de águas. Finalmente foi associado às condições topográficas e urbanas das áreas da quadrícula.

\section{Resultados e discussão}

A RPA 4 possui grande área vegetada, onde a resposta do modelo de fluxo de escoamento corresponde a rios, como exemplo a quadrícula de amostragem 80_09-00 (Figuras 2 e 3), ou áreas rebaixadas com capacidade de realizar os processos hidrológicos naturais tal como a infiltração.

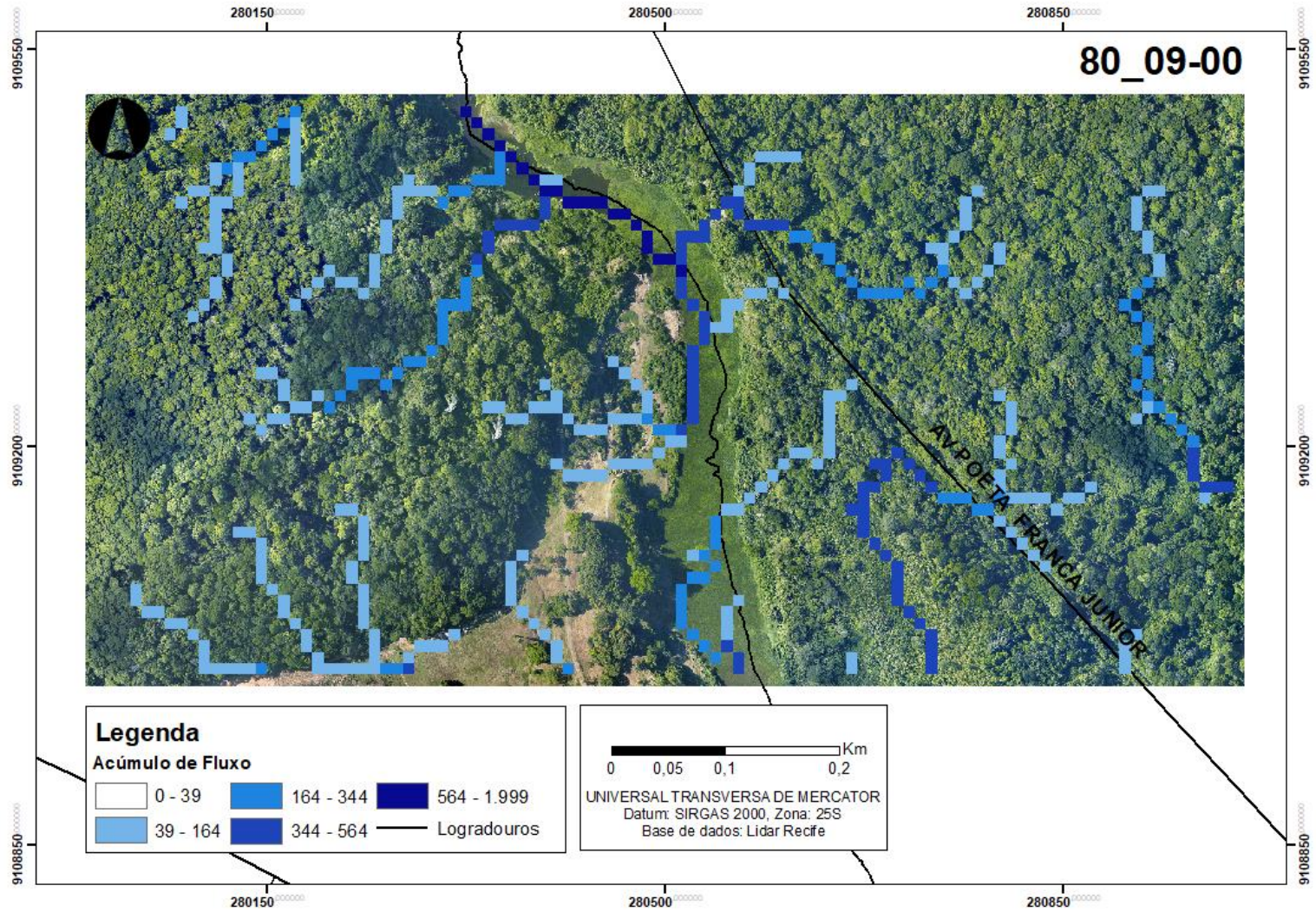

Figura 2: Acúmulo de fluxo da quadrícula de amostragem 80 09-00, Região político-administrativa 04.

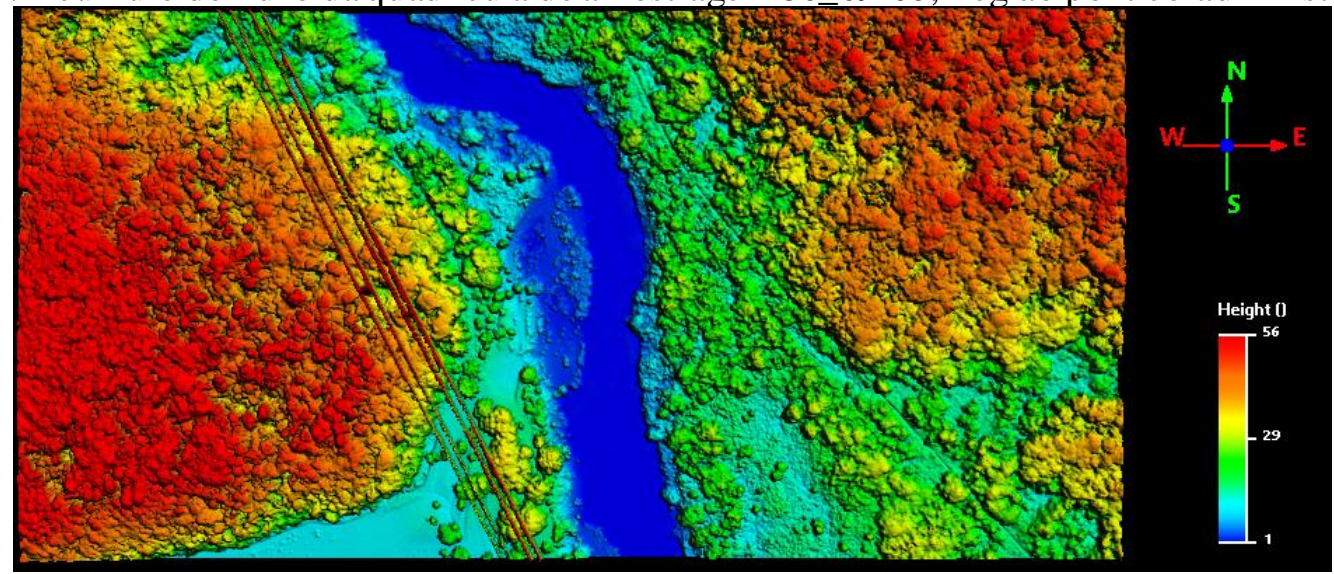

Figura 3: MDE da quadrícula de amostragem 80_09-00.

Lima; A. S., Bandim; C. G. A., Soares; G. A. S., Barros; J. P. F. G., Galvíncio, J. D. 
A quadrícula 80_09-00 está localizada na zona oeste do Recife, mais especificamente no entorno da avenida Poeta França Junior no bairro da Várzea, na RPA 04, Figura 2. Diferente da maioria das áreas de amostragem utilizadas nesse trabalho, essa quadrícula apresenta uma área com um baixo índice de ocupação do solo, isso se dá pelo fato dela estar inserida em uma área de preservação ambiental da mata da Várzea, no âmbito da bacia do Rio Capibaribe, e possui uma área total de mais de 700 hectares, nela também é possível encontrar-se uma vegetação remanescente da Mata Atlântica e alguns pontos de cultura de subsistência.

Em função dessa área de preservação a dinâmica hidrológica vai ocorrer de forma diferente dos outros locais, apresentando assim um caráter mais natural. Alguns elementos que estão presentes na dinâmica natural vão ser os principais influenciadores na ocorrência das enchentes nesse local. A intensidade dos eventos pluviométricos vai ser um dos principais fatores presentes na ocorrência das enchentes nesse local, isso se intensifica ainda mais quando paramos para observar os eventos meteorológicos que ocorrem na cidade. Segundo Souza (2012), cerca de cinco sistemas meteorológicos são responsáveis pela ocorrência de precipitação na cidade do Recife, são eles: as Ondas de Leste, a Zona de Convergência Intertropical, instabilidade geradas pelas Frentes frias, Vórtices Ciclônicos de Ar Superior e os Sistemas de Brisas. Esses sistemas seriam os principais reguladores meteorológicos da cidade do Recife.

Além dos eventos pluviométricos, outro fator que mostra uma influência no acúmulo de água superficial é a geomorfologia, a parte do Rio Capibaribe que é representada nessa amostra é circundada por um relevo mais elevado, essa elevação no relevo faz com a água que é infiltrada no solo seja escoada para a parte mais plana da quadrícula, nesse caso a parte mais plana é o leito do rio, elevando a saturação do solo e enchente das áreas de várzea.

Um outro fator que não é tão abordado é a influência da cobertura florestal na interceptação da água da chuva, o tipo de cobertura vai afetar diretamente na quantidade de água que vai ser perdida durante o processo de precipitação. Para Moura (2009), o formato da cobertura, a área foliar e a estrutura da casca são considerados fatoreschave para se determinar a capacidade de armazenamento no dossel. Desse modo pode-se chegar a interpretação de que se uma área possui uma cobertura florestal reduzida ou se a estrutura da cobertura não for tão consistente a quantidade de água retida no dossel das árvores vai ser menor e a quantidade de água disponível no solo vai ser maior. $\mathrm{Na}$ área em questão a cobertura florestal demonstra densidade, o que facilita retenção da precipitação através da interceptação, no entanto, nas áreas próximas às margens que não possuem essa cobertura e próxima à avenida é possível notarmos acúmulo superficial de água.

A quadrícula 81_31-00, cujo mapa de acúmulo de fluxo corresponde a Figura 4, possui relevo peculiar que direciona o fluxo a espécie de um canal temporário no ponto mais rebaixado a noroeste da rua Gustavo Vidigal, no qual se concentra o maior índice de escoamento, a análise do MDE demonstra uma área rebaixa em tomo de 9 metros circundada por altitudes que variam entre 20 e 30 metros, Figura 5. É possível observar três fluxos secundários a oeste que escoam para área mais rebaixada, assim como parte do fluxo da rua Gustavo Vidigal que juntos alimentam o acúmulo de água da região em questão. A quadrícula tem baixa suscetibilidade a inundações por ter grande parte de área vegetal o que permite a infiltração, e mais, o modelo de acúmulo de fluxo demonstra que somente as ruas Graminei e Gustavo Vidigal sofrem com alagamentos de médio e baixo impacto, o que se deve a estarem alocadas na região mais rebaixada da quadrícula.

Em particular a rua Gustavo Vidigal, vale destacar, tem acúmulo de escoamento concentrado a norte, ponto mais suscetível a inundações, decorrente da impermeabilização do solo e condição do relevo, é perceptível que o fluxo advindo da parte superior mais elevada sofre bloqueio da água que escoa até o ponto mais rebaixado no cruzamento com a rua Gramineia. 


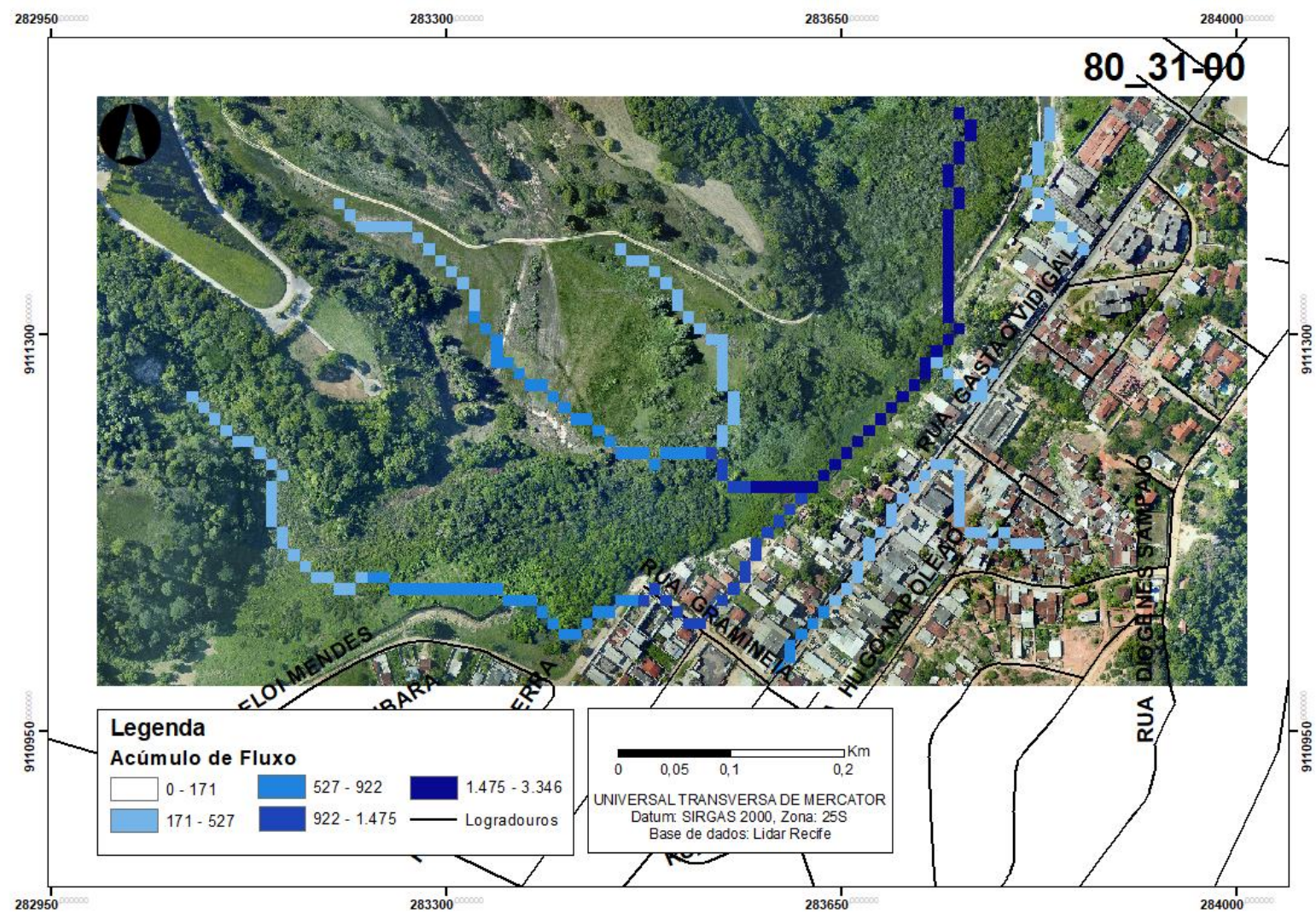

Figura 4: Acúmulo de fluxo da quadrícula de amostragem 81_31-00, Região político-administrativa 04.

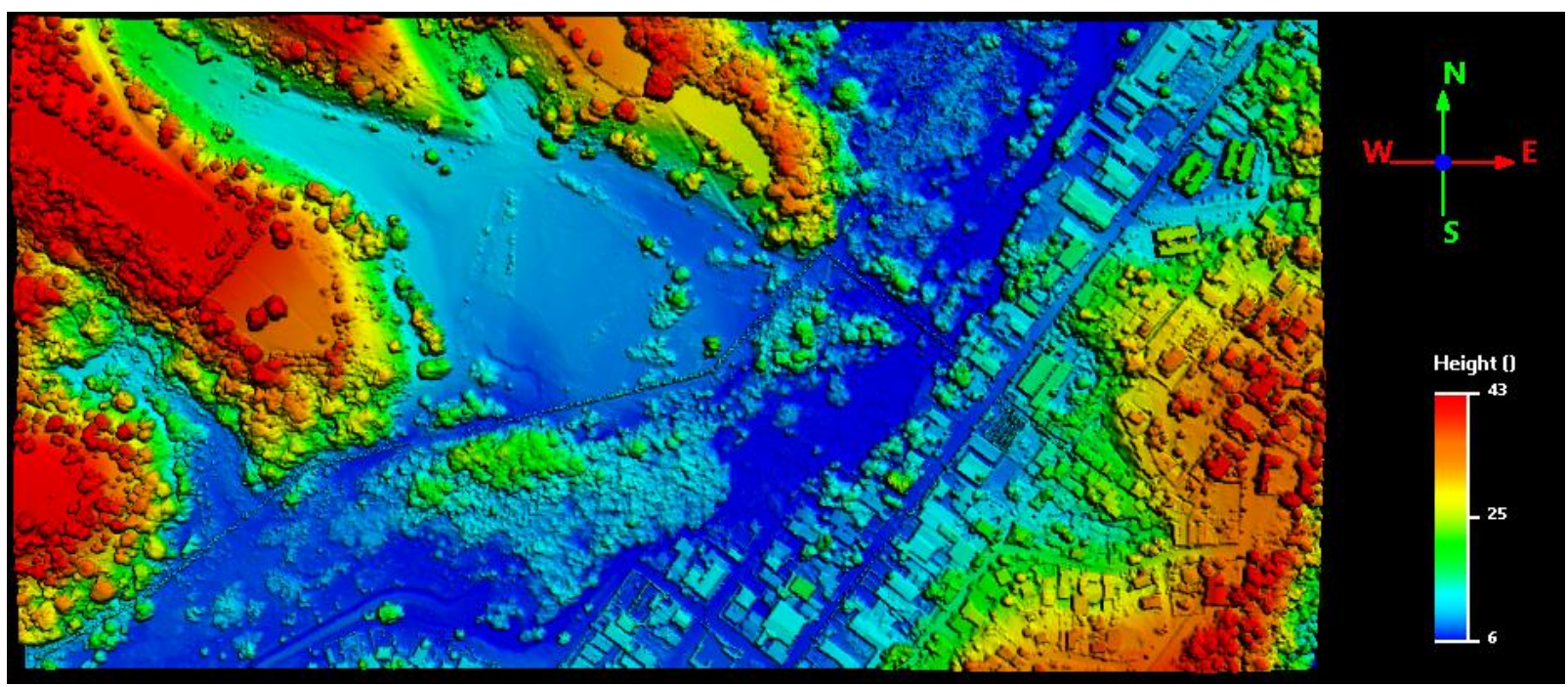

Figura 5: MDE da quadrícula de amostragem 81_31-00.

Uma das áreas selecionadas paraanálise na RPA 04, popularmente conhecidacomo zonaOeste do Recife, foi a correspondente à quadrícula 80_49-00 do PE3D, Figura 6. Nesta quadrícula, estão incluídos os bairros da Várzea e a Cidade
Universitária. Os bairros supracitados estão situados em uma área de forte atividade econômica e de grande importância para a cidade do Recife, e em decorrência de tal fator, são fortemente urbanizados. Segundo dados do censo demográfico 
do IBGE, publicado em 2010, o bairro da Várzea possui um total de 70.453 habitantes residentes; enquanto no bairro da Cidade Universitária, foram contabilizados apenas 818 habitantes residentes. Além da população residente, há ainda nesses bairros um fluxo enorme de pessoas diariamente, em decorrência da gama de serviços presentes em seus arredores, tais como a Universidade Federal de Pernambuco. (IBGE, 2010).

Como resultado do intenso processo de desenvolvimento urbano surgem algumas problemáticas, tais como o aumento da velocidade de escoamento das águas pluviais em decorrência da impermeabilização do solo, a redução do tempo de concentração na bacia, o aumento e antecipação na vazão de pico, o aumento da produção de sedimentos e de resíduos sólidos. A ocupação das áreas de várzea dos rios, é um outro problema recorrente nos grandes centros urbanos, já que os rios possuem suas próprias dinâmicas naturais, e suas enchentes periódicas onde o leito maior do rio é ocupado em resposta à eventos pluviométrico extremos, desencadeiam problemas diversos à população reside. A área em análise, está inserida na Bacia do Rio Capibaribe, o principal rio para a macrodrenagem da cidade do Recife. Somado aos grandes índices pluviométricos da cidade do Recife, esse rio já protagonizou diversas situações de enchentes ao longo dos anos, destaque para a dos anos 70, que levou à realocação de residentes de áreas de várzea afetados para diversas Unidades Residências (URs) construídas pelo governo em áreas de maior altitude. Ainda assim, a ocupação das áreas de várzeas dos rios ainda é intensa hoje, sendo o bairro da Várzea um dos mais populosos da capital. (Girão, 2007; Tucci, 1993; 2009).

A quadrícula 80_49-00, Figuras 6 e 7 , apresenta diferenças consideráveis em seu território, sendo a dicotomia espacial entre a presença de áreas verdes em alguns espaços a principal delas, em contrapartida ao grande adensamento populacional em outras áreas, o que justifica um comportamento diferente das águas pluviais. Enquanto a infiltração da água advinda das chuvas é alta em áreas que possuem cobertura vegetal, o que resulta em uma diminuição no escoamento superficial e maior acúmulo de fluxo. Em áreas onde a cobertura vegetal foi retirada, e o solo foi coberto por materiais impermeáveis, a água encontra resistência na infiltração, o que acaba por intensificar o escoamento superficial e resultar em acúmulos de água em espaços antropizados (Tucci, 1997).
Na quadrícula em questão, alguns pontos de análise merecem uma devida atenção, por registrar um maior acúmulo de fluxo, como algumas localidades do campus Reitor Joaquim Amazonas da UFPE, em especial áreas com presença de cobertura vegetal e a Avenida da Arquitetura. Para além da Cidade Universitária, no bairro da Várzea também são encontradas localidades que apresentam acúmulo de água significativo, como a Rua Santa Dorotéia, e no encontro entre as ruas Belém de São Francisco e João Francisco de Lisboa.

Nos pontos vegetados da UFPE, o acúmulo considerável de água, se dá em decorrência da manutenção de algumas dinâmicas naturais no espaço inalterado, ou pouco antropizado, que conduz a água advinda da chuva para pontos onde o solo, ainda permeável, consegue infiltrar essa água. É possível visualizar pontos com essa característica no campus da UFPE, na porção nordeste da quadrícula, e em localidades vegetadas circundantes à Avenida da Arquitetura. Mais à sudeste na quadrícula, é possível identificar um grande acúmulo de água na Avenida supracitada, decorrente da impermeabilização daquela área, resultante das construções presentes, como os prédios da universidade e as ruas e avenidas. Essas construções alteram o curso natural da água, e impedem a infiltração, o que finda em acúmulos superficiais, também conhecidos como inundações urbanas (FLOOD SITE, 2019).

As ruas João Francisco Lisboa e Belém de São Francisco, possuem em seu encontro um outro ponto significativo de alagamento, decorrente principalmente das mesmas questões que findam no acúmulo na Avenida da Arquitetura, porém neste caso tais problemas são intensificados, como consequência do grande adensamento populacional. As ruas impermeabilizadas, assumem a função de corredores, por onde as águas pluviais são conduzidas até os pontos mais rebaixados, e se acumulam. O mesmo ocorre na Rua Santa Dorotéia, localizada na porção sudoeste da quadrícula, que apesar de não ser pavimentada, possui um extensocorredorde casas que conduzem a água até esse espaço. Pela baixa capacidade de absorção do solo, que apesar de não ser pavimentado, teve sua cobertura vegetal natural retirada, e consequentemente grande perdaem seus níveis de absorção. 


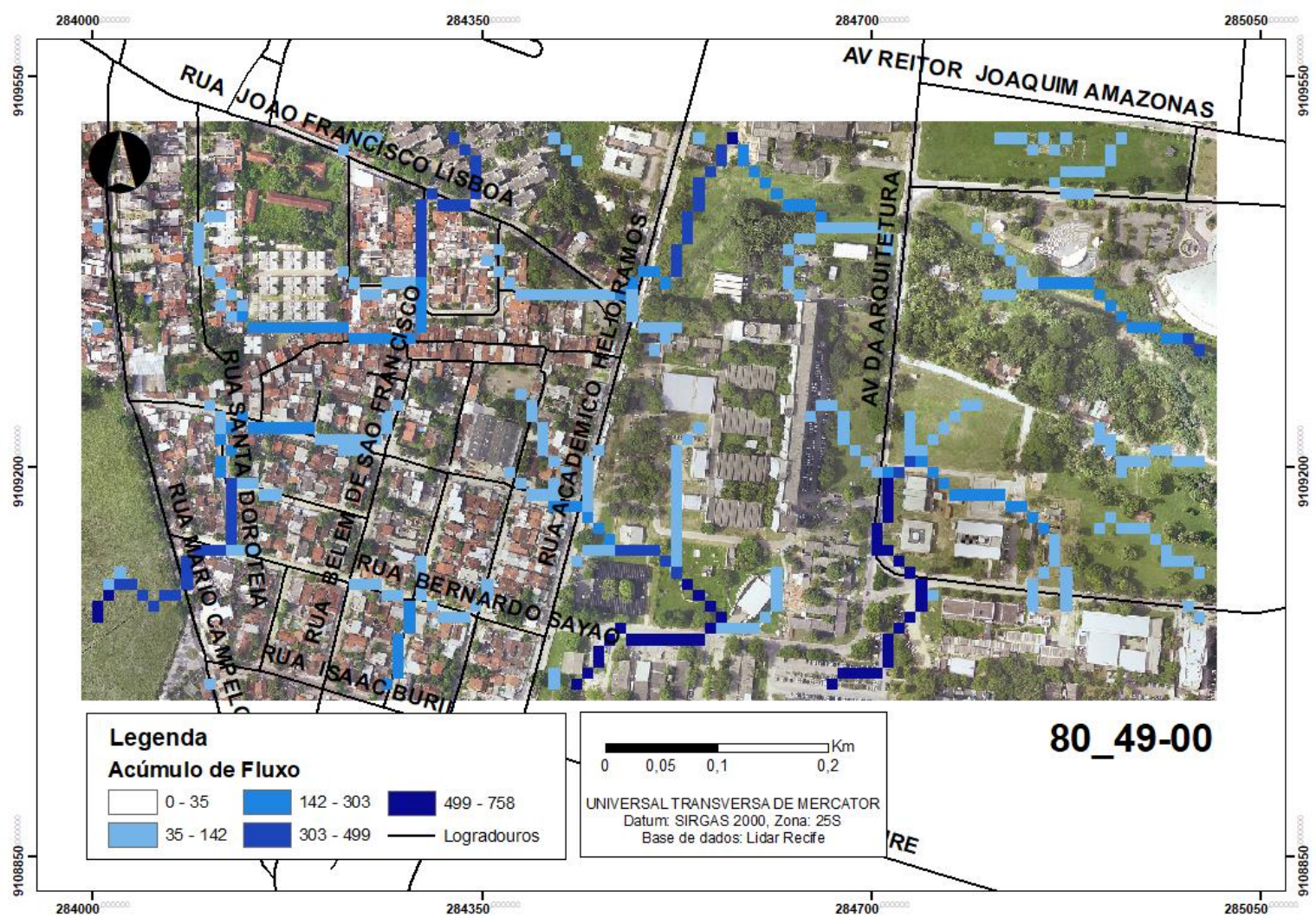

Figura 6: Modelo de acúmulo de fluxo da quadrícula de amostragem 80_49-00, Região políticoadministrativa 04.

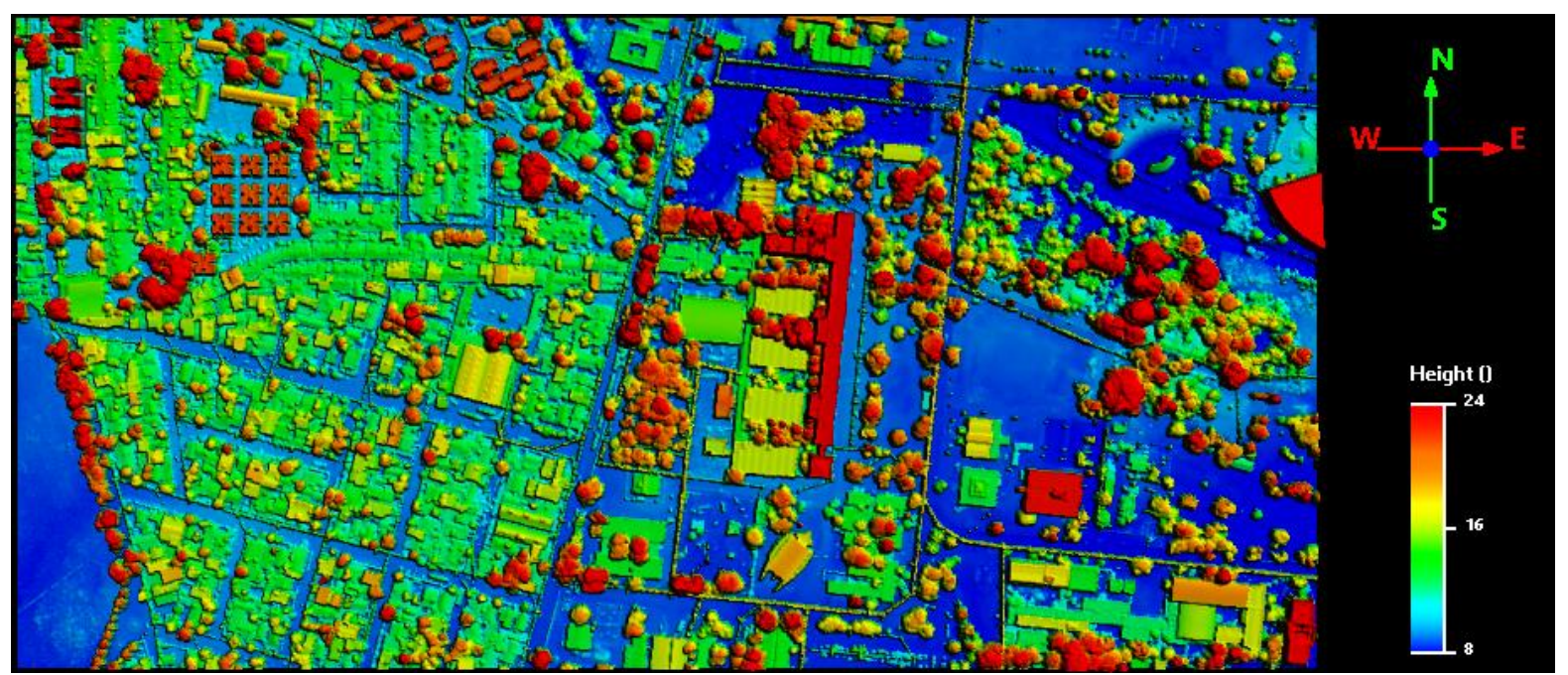

Figura 7: MDE da quadrícula de amostragem 80_49-00.

A área estudada corresponde a quadrícula 80_60-05, localizada no bairro da Várzea, Figuras 8 e 9 . As distintas intensidades presentes nos acúmulos se caracterizam através das diferentes declividades dos acidentes topográficos, ou seja, pontos com depressões acentuadas e outras densas.
Com tudo, existem áreas menos depressivas que apresentam uma intensa junção de águas, isso ocorre devido ao adensamento de áreas construídas. Assim diversos locais com diferentes níveis de alagamento são visíveis, porém o estudo delimitou-se apenas a 2 pontos que merecem 
destaque, estes se referem a área pertencente a rua David Nasser e parte da Avenida Caxangá (Figura 4).

A parte correspondente a Avenida Caxangá apresenta uma área menos acentuada, contudo o acúmulo em questão é intenso. O local inundável em questão afeta uma grande parte da população recifense por esta localizado ao Sul da quadrícula e em meio á uma das maiores avenidas em linha reta do Brasil. O acúmulo ocorre devido a 3 fatores essenciais: primeiro a impermeabilização do solo, pois com isso o escoamento superficial se intensifica em velocidade aumentando seu volume rapidamente, transformando o ambiente urbano em uma espécie de lago com a intensidade dos processos hídricos, assim como Gonçalves e Nucci (2017) apontam o aumento da velocidade do escoamento das águas pluviais por causa da impermeabilização como principal fator para inundações, pois diminui o tempo de alcance a vazão, que nesse caso seria os mecanismos de drenagem em meio urbano; segundo as leis de Newton (1887), que estão essencialmente ligadas a presença do viaduto do Bus Rapid Transit (BRT). $O$ viaduto opera como intensificador e obstáculo para o percurso das águas pluviais, impulsionando a velocidade de acordo com o volume de massa (chuva) interceptada sobre o mesmo e reagindo com acúmulos de água na medida que chegam a parte mais baixa, onde sofre o barramento. Portoet. al (2012), já comentavam que alterações no espaço físico-espacial no meio urbano como impermeabilização, edificações, canalizações entre outros, causam mudanças severas no escoamento da água e isso pode tornar essas mudanças permanentes na dinâmica hídrica; Terceiro, o sistema de microdrenagem presente nesse trecho. Os dispositivos de drenagem para esse trecho é composto apenas por bocas de lobos e grades, compostas por entradas aparentemente pequenas em relação ao volume de águarecebido, além disso a degradação desses dispositivos pode ser considerado um problema, os responsáveis por essas degradação podem ser a falta de manutenção e o acúmulo de lixo domésticos direcionados exclusivamente a esses itens de planejamento urbano, principalmente para as Bocas de lobos, devido ao dispositivo de entrada tipo caixa aberta, isso pode resultar em uma sobrecarga e causar um déficit na drenagem.

Por outro lado, ao norte da quadrícula, a esquerda da rua David Nasser, se situa uma área bastante depressiva como observa-se o modelo MDE, porém o acúmulo apresenta-se menos intenso, com valores entre 62 e 254 pontos de fluxos (Figura 5). Essa área trata-se da localização do Hospital Barão de Lucena no bairro Iputinga, mesmo o terreno estando em espaço depressivo é contemplado com a presença de uma considerável vegetação, sendo estas árvores altas com grandes dosséis e vegetação rasteiras com alguns arbustos, isso influencia na interceptação e retenção das águas pluviais, permitindo ocorrer o processo natural de drenagem. De acordo com Tucci e Bertoni (2003), aproximadamente $90 \%$ da água em ambientes inalterados ou pré-urbanizado conseguem atingir o processo natural de infiltração ou/e evapotranspiração, diferentemente de um ambiente fortemente urbanizado, onde mais de $70 \%$ escoam sobre as superfícies impermeáveis. Gonçalves e Nucci (2017) colocam a impermeabilização do solo e a drenagem convencional como fatores relevantes para o controle de inundações urbanas, isso devido a desconsideração dos processos hídricos naturais em relação ao uso do solo. Isso afirma como as áreas construídas influenciam diretamente nos alagamentos em meio a cidade e como faz-se necessário a revisão do sistema de macro e micro drenagem. 


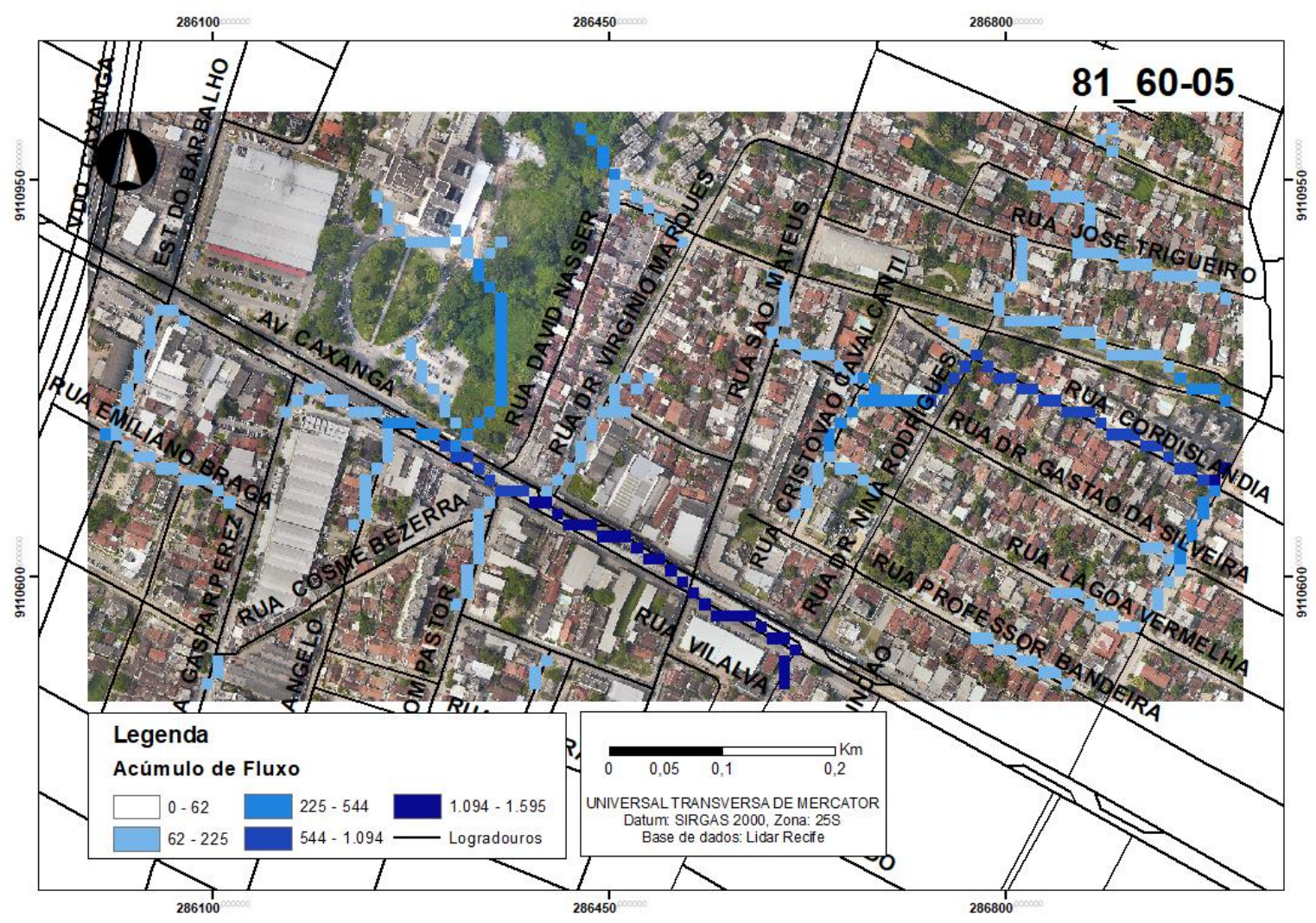

Figura 8: Acúmulo de fluxo da quadrícula de amostragem 81_60-05, Região político-administrativa 04.

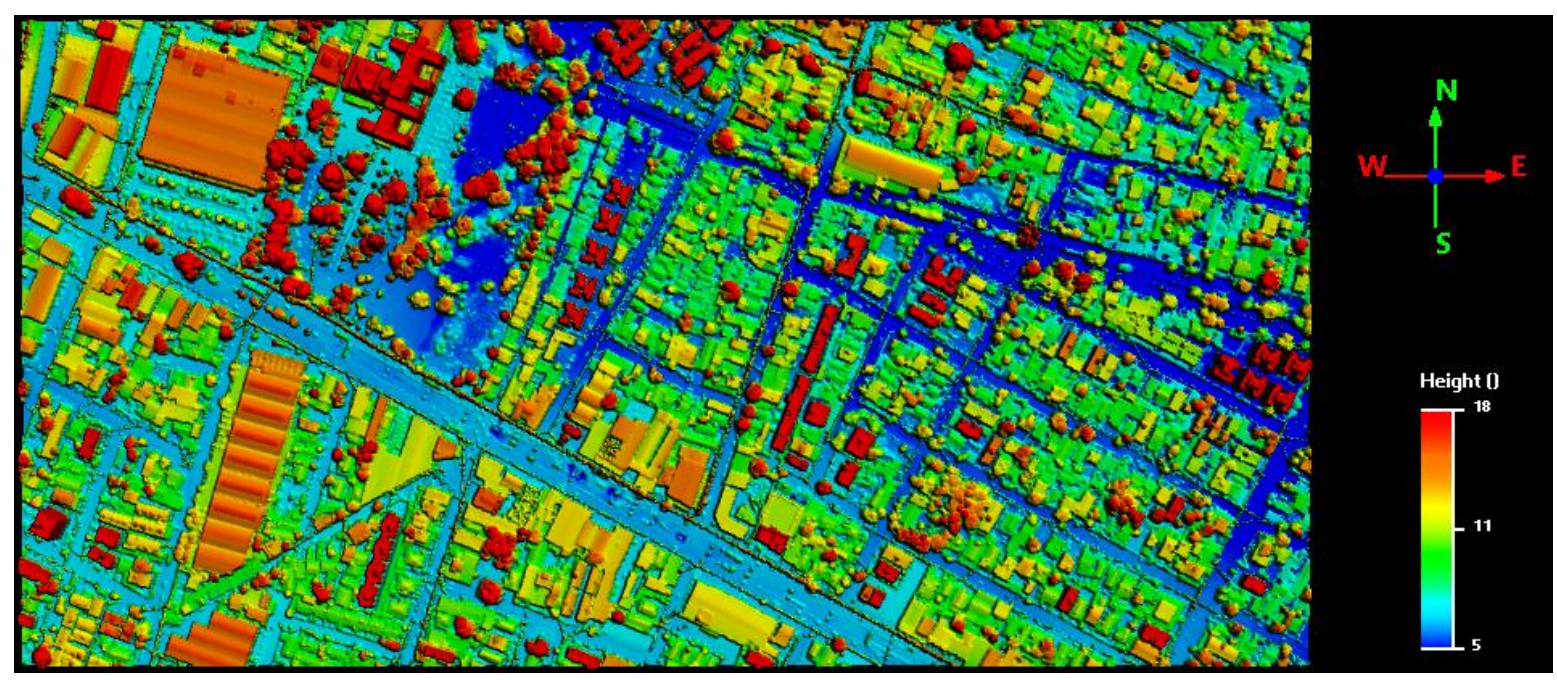

Figura 9: MDE da quadrícula de amostragem 81_60-05.

Os resultados obtidos sobre a quadrícula 80_99-05, Figuras 10e 11, localizada na zonaoeste no bairro da Madalena, apresentam visivelmente um terreno completamente dominado pelo uso e ocupação, ainda conta com a presença de pouquíssimas árvores de porte médio que ornamentam algumas ruas, porém o que chama de fato a atenção nessa área é a quantidade de edificações. A topografia mostra-se bastante homogênea em grande parcela da quadrícula (Figura 11), constituída por cotas altimétricas consideráveis com pouca diferenciação, contudo os espaços com maiores depressão se concentram nas partes inferiores Sul, Sudeste e Sudoeste do MDE 


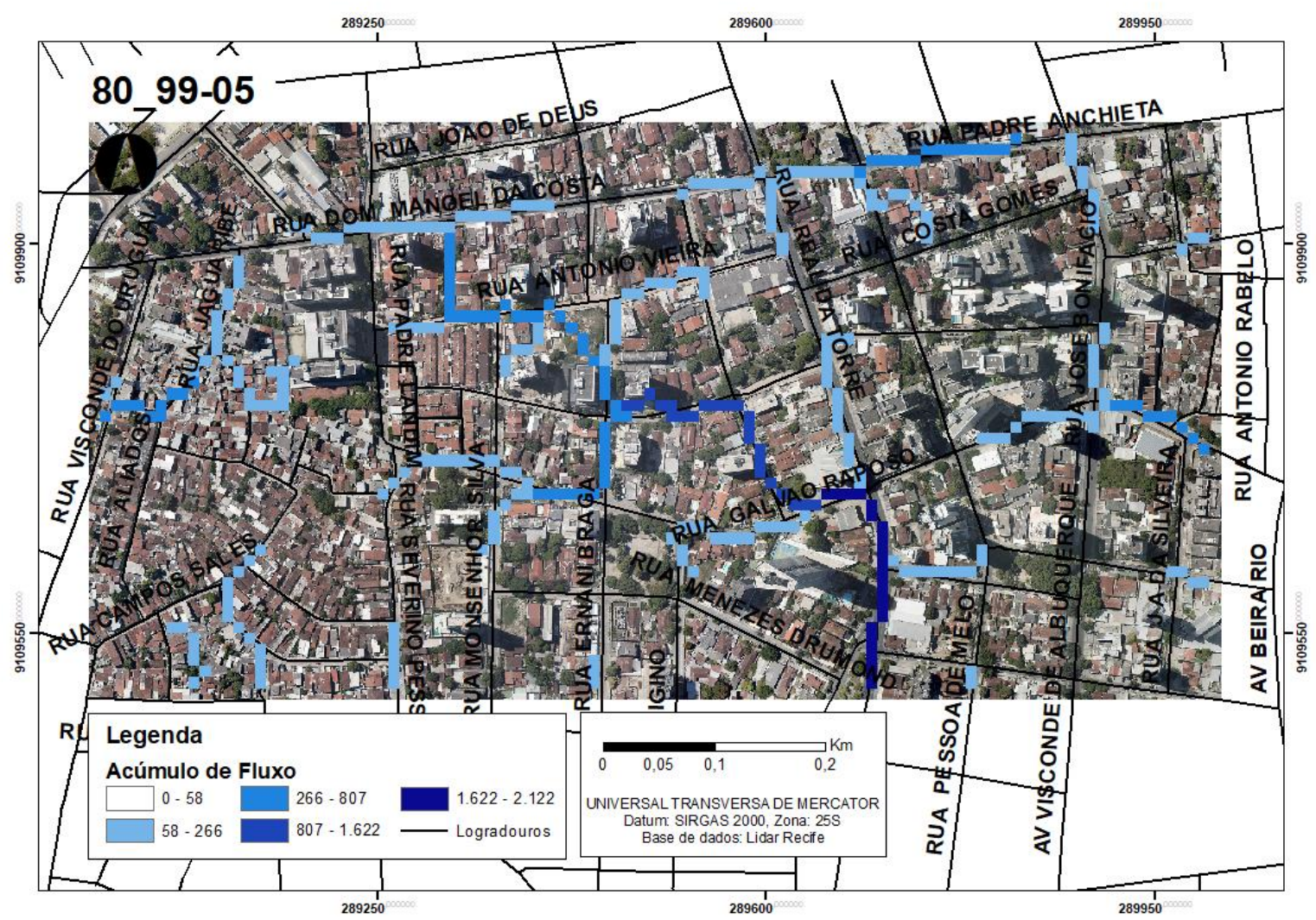

Figura 10: Acúmulo de fluxo da quadrícula de amostragem 80_99-05, Região político-administrativa 04.

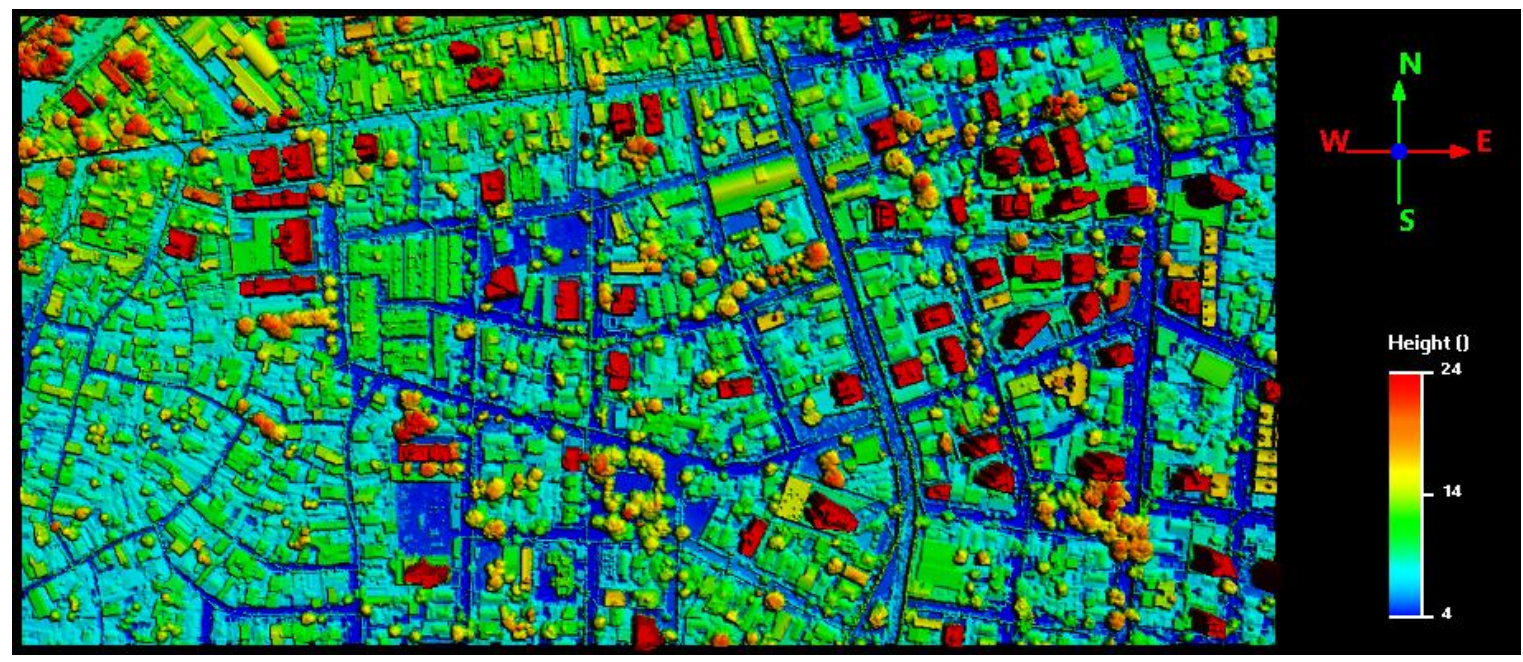

Figura 11: MDE da quadrícula de amostragem 80_99-05. 
De acordo com Tucci (2004) a influência das obras antrópicas sobre o terreno é notável, implicando desajustes consideráveis no percurso do escoamento superficial. A impermeabilização do solo auxilia a intensificação da velocidade e volume dos níveis de águas no meio urbano impedindo a infiltração por meio natural.

Nos modelos de acúmulo de fluxo, em geral, os índices variam de 58 a 266 pontos de fluxos situando-se na parte mais igualitária em declive do terreno, entretanto índices entre 807 e 2.122 pontos e se apresentam menos localidades, estes se encontram nas áreas mais depressivas seja natural ou provocadas pelo homem. As ruas e vias de tráfego em relação a essa quadrícula possui um importante efeito sobre o escoamento sendo visivelmente notável no modelo de acúmulo de fluxo, segundo Gallegos et. al (2010) às ruas trabalham como uma espécie de canais que direciona as águas superficiais para terrenos com cotas rebaixadas, sendo necessária a resolução da altimetria através de modelos hidrológicos assim como os edifícios que funcionam como barreiras semelhantes a altos relevos.

Contudo esse estudo ver a necessidade de colocar em ênfase a área que apresenta maior quantidade em acúmulo de fluxo seja por questões naturais ou artificiais, está se concentra nos sentidos norte e sul da Rua Galvão Raposo. Os acúmulos situam-se exatamente nos espaços com maiores depressões nas partes inferiores da quadrícula (Figura 6), onde as águas pluviais tendem a confluir e depositar, seguindo os padrões naturais de escoamento. Carvalho e Silva (2006) apontam que o relevo e suas características morfométricas se ligam diretamente as dinâmicas de escoamento e consequentemente de drenagem, considerando o escoamento superficial natural como um dos estudos mais importante do ciclo hidrológico. Além das áreas depressivas o terreno é fortemente impermeável contribuindo para o aumento de volume de água, porém o grande astro em questão se trata das áreas construídas verticalmente, ou seja, os edifícios e/ou prédios. Os fixos interferem na rotina original do percurso dos fluxos de água tendo um impacto considerável sobre os alagamentos, assim como afirmam Hervouet et al. (2000) que as inundações em espaços urbanos sofrem com a elevação na extensão das cheias devido ao impacto dos fixos, comparando assim com uma área de planície de inundação não desenvolvida. Isso apenas reforça o quão se faz importante o planejamento urbano de acordos com medidas previstas no Plano diretor de drenagem urbana, fazendo as adaptações necessárias para nosso país.

A RPA 06, localizada na zona Sul do Recife, é composta pelas quadrículas de amostragem 80_51-00, 80_82-05, 90_01-05, 80_94-05 e 90_25-05, Figura 7. Em contrapartida a RPA 04 a região possui poucos núcleos vegetados aliado a alta taxa de urbanização, é perceptível através da análise da amostragem a diferente densidade populacional da região o que finda a suscetibilidade mais significativas de inundações urbanas pelas mudanças latentes ao padrão natural de escoamento. E mais, os modelos de fluxo apresentam resultados mais suscetíveis a inundações, uma vez que que a água pluvial não infiltra no solo e as redes de microdrenagem e macrodrenagem não suprem a demanda volumétrica.

Entre as áreas selecionadas para análise na RPA 06, popularmente conhecida como zona Sul do Recife, se encontra a quadrícula 80_51-00 do PE3D, Figuras 12 e 13. Estão incluídos no território da quadrícula os bairros da Cohab e o Ibura, que estãolocalizadosem uma áreaperiférica da zona mais valorizada dacidade do Recife. Como resultado da supervalorização de bairros inseridos em uma área de planície e mais próximos ao litoral, casos como o de Boa Viagem e Pina, os bairros de uma região mais periférica, sofreram um inchaço populacional pelo redirecionamento da população menos favorecida para estes espaços menos valorizados. Um outro fator determinante para ocupação dos bairros supracitados, foi o grande deslocamento ocasionado pelas enchentes dos rios Capibaribe e Beberibe em meados de 1960 e 1970, onde os moradores das áreas afetadas foram realocados para as URs, unidades residenciais construídas pelo governo. Segundo dados do censo demográfico do IBGE, publicadoem 2010, o bairro da Cohab possui um total de 67.283 habitantes residentes; enquanto no Ibura, foram contabilizados 50.617 habitantesresidentes (IBGE, 2010).

Na quadrícula 81_51-00, Figuras 12 e 13, algumas áreas se destacam no mapa de acúmulo de fluxo, por apresentarem alagamentos mais intensos. Na porção nordeste e sudeste da quadrícula, entre as ruas Nova América e Amparo no bairro do Ibura, é possível identificar alguns pontos de acúmulo de água de baixa intensidade, em decorrência da ele vação do terreno, que possui 
elevação de até mais que $70 \mathrm{~m}$ ao decorrer da rua Nova América. Ainda que em baixa intensidade, esse acúmulo é escoado para áreas mais baixas, nesse caso, para rodoviafederal BR-101 quepossui altitude variando entre $20 \mathrm{~m}$ e $40 \mathrm{~m}$ neste trecho, e que pode ser observada nesta quadrícula como principal ponto de acúmulo, como consequência dos fluxos das áreas mais elevadas à leste e à oeste, confluírem para este ponto de topografia mais rebaixada.

Á esquerda da BR-101, sentido oeste na quadrícula, ocorre um caso semelhante ao anteriormente explanado, o fluxo de escoamento segue de um ponto mais alto para um mais baixo, originando-se nas travessas Dois Rios e Guaraciaba no bairro da Cohab, área de cerca de 50 $\mathrm{m}$ de altitude; seguindo pela rua Magda, que nesse caso funciona como um canal para o fluxo e onde há um acúmulo maior em dec orrência de sua menor altitude, cerca de $30 \mathrm{~m}$; e por fim, acumulando na BR-101, área mais rebaixada do terreno.

Ainda no bairro da Cohab, porém em uma área mais distanciada da rodovia, há uma nova concentração de pontos que acumulam água superficial na quadrícula 81-51-00. Se tratando da porção com menores índices altimétricos da quadrícula, em torno dos $30 \mathrm{~m}$ de altitude, a porção oeste da quadrícula apresenta altos índices de acúmulo. Apesar de mínima, nesta porção da quadrícula é possível enxergar alguma vegetação, porém, no espaço ainda predomina a retirada da cobertura vegetal e a consequente impermeabilização do solo para construção de residências, o que pode ser apontado como principal fator determinante para o elevado acúmulo ali presente. Os principais fluxos são oriundos do centro da quadrícula, onde duas ramificações de fluxos distintas convergem e seguem para rua Vale do Itajaí, uma área mais rebaixada, com cerca de $25 \mathrm{~m}$ de altitude. Outro fluxo presente, e convergente na rua Vale do Itajaí, são os advindos da rua Asa Branco, os fluxos não são intensos, porém, quando em convergência com outros fluxos presentes na área, alcança um nível elevado de água acumulada na superfície. Por fim, o fluxo na rua Vale do Itajaí se ramifica e segue em dois rumos, um de baixa intensidade para a rua Deputado Luiz Dias Lins e outro mais intenso para uma região arborizada no fim da porção sudoeste da quadrícula, mostrando que quando há presença de vegetação, a água segue seu curso natural para estas áreas onde provavelmente infiltrará.

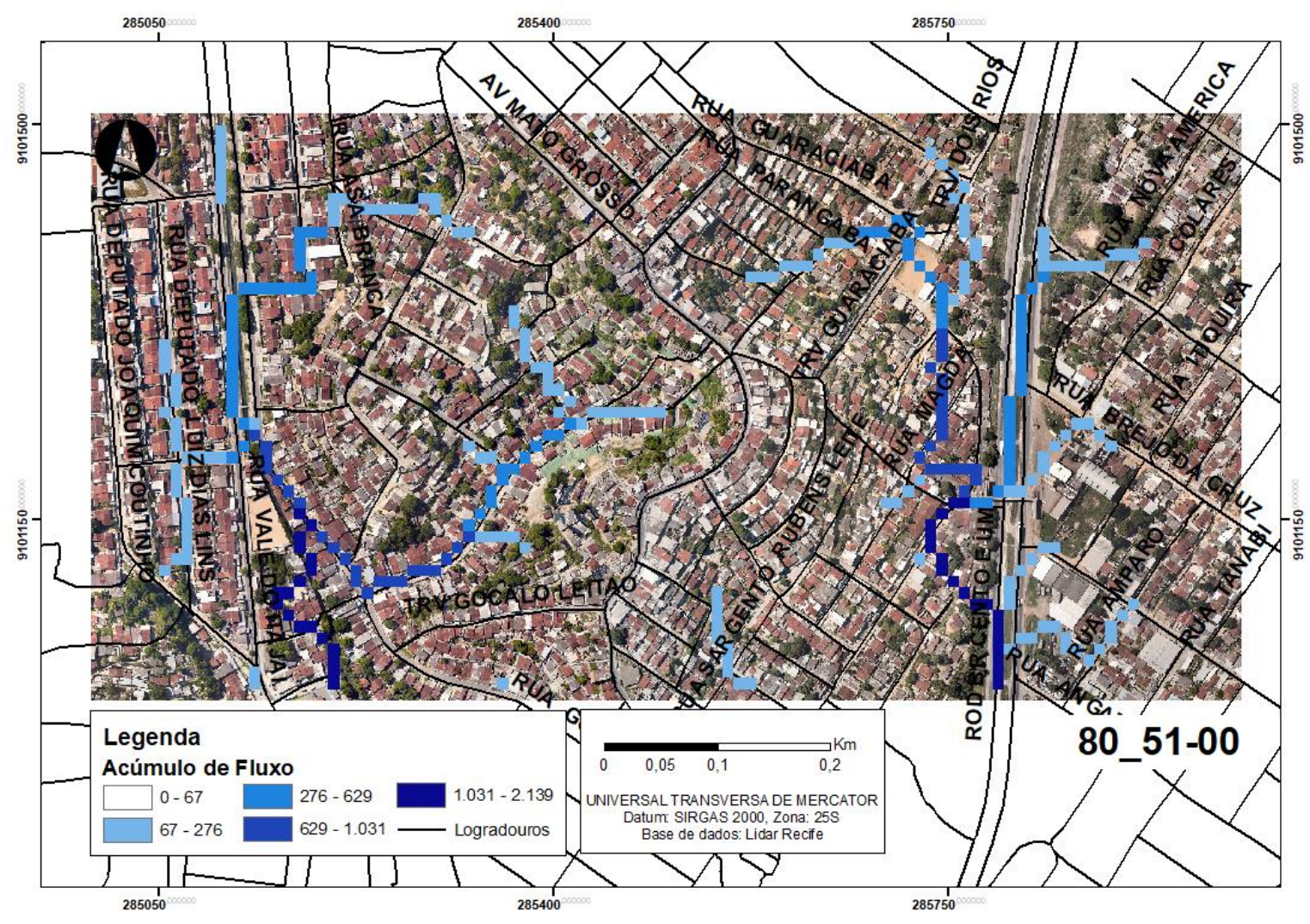

Figura 12: Acúmulo de fluxo da quadrícula de amostragem 80_51-00, Região político-administrativa 06.

Lima; A. S., Bandim; C. G. A., Soares; G. A. S., Barros; J. P. F. G., Galvíncio, J. D. 


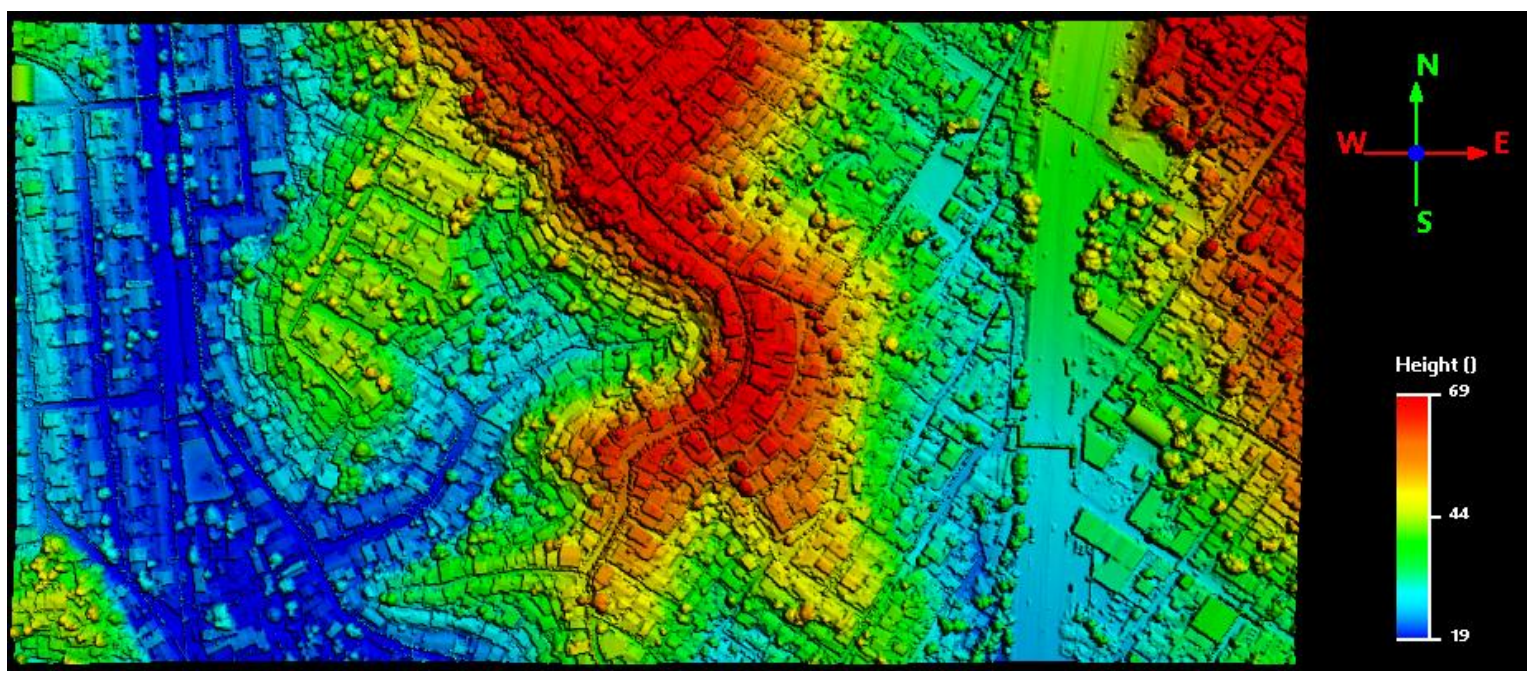

Figura 13: MDE da quadrícula de amostragem 80_51-00.

Uma outra área selecionada para análise na RPA 06, foi a correspondente à quadrícula 80_8205 do PE3D, Figuras 14 e 15 . Nesta quadrícula está inserido apenas o bairro da zona sul do Recife, Ipsep. O bairro em questão se destaca pela sua proximidade aos bairros mais nobres da região, Boa Viagem por exemplo, e a gama de serviços e lazeres que sua redondeza pode oferecer. Em decorrência de sua valorizada vizinhança, o Ipsep acabou por se tornar uma opção de residência para aqueles que desejavam estar próximos a variedade de serviços presentes na área nobre da zona sul, porém não possuía poder aquisitivo suficiente para morar na beira-mar. Segundo dados do censo demográfico do IBGE, publicado em 2010, o bairro do Ipsep possui um total de 25.029 habitantes residentes. Idealizado inicialmente como um núcleo residencial para moradia dos servidores estaduais de Pernambuco, e financiado pelo Instituto de Previdência dos Servidores do Estado de Pernambuco, o Ipsep se estabeleceu primeiramente como umavila, e posteriormente foi reconhecido como um bairro da região metropolitana do Recife. (Carvalho, 2018; IBGE, 2010).

O bairro do Ipsep corresponde à uma área rica em recursos naturais, por estar localizada em uma área próxima aos vestígios de manguezais presentes na zona oeste do Recife, banhada pelo Rio Tejipió. Além de estar inserida em uma planície costeira, e próxima a zona costeira. Todos esses fatores influenciam diretamente no comportamento hídrico no bairro do Ipsep, e resultam nos alagamentos e inundações observáveis na quadrícula 80_82-05.

No que tange à quadrícula 80_82-05, é possível visualizar a ocorrência de diversos acúmulos de fluxo distribuídos por toda a área em estudo. É curioso destacar ainda, que nesta quadrícula, as ruas funcionam claramente como canais de condução desse fluxo pluvial, e conduzem a água acumulada para as partes mais rebaixadas do relevo. Apesar de os elementos supracitados, tais como a presença de manguezais e da área litorânea, não estarem presentes nessa quadrícula em especial, eles influenciam de forma direta no comportamento das águas superficiais da área em análise (Gallegos, 2010).

Alguns pontos mais severos de acúmulo superficial na quadrícula em análise devem ser destacados, ainda que os fluxos ocorram de forma regular por praticamente todas as ruas da quadrícula como consequência de se tratar de uma área de planície, e de seu terreno possuir altitudes consideravelmente niveladas. $O$ primeiro acúmulo intenso ocorre ao norte da quadrícula na rua Rio Maranhão, o fluxo desse acúmulo é conduzido por dentre as ruas e sofre uma bifurcação na rua Rio Amazonas, onde é conduzido à uma área vegetada presente na rua, no sentido leste; no seinto oeste, $o$ fluxo percorre um total de $254 \mathrm{~m}$, onde finalmente estaciona na Rua Jean Emile Favre, comprovando o protagonismo das ruas como direcionadoras do fluxo. Outro ponto pode de forte acúmulo conduzido pelas ruas pode ser visualizado na rua Rio Itororó, onde parte do acúmulo segue para o 
mesmo terreno vegetado que o fluxo do Rio Amazonas, e parte segue para a rua Rio Colorado. Pode-se observar nesta quadrícula o grande impacto da impermeabilização do solo e da construção de residências nas dinâmicas hídricas naturais dos locais, já que a água percorre por diversas ruas e não consegue ser completamente retida em nenhum solo, evidenciando também o quão as construções humanas impedem a água de seguir seu curso natural, como evidência Brown (2007) em suas conclusões.

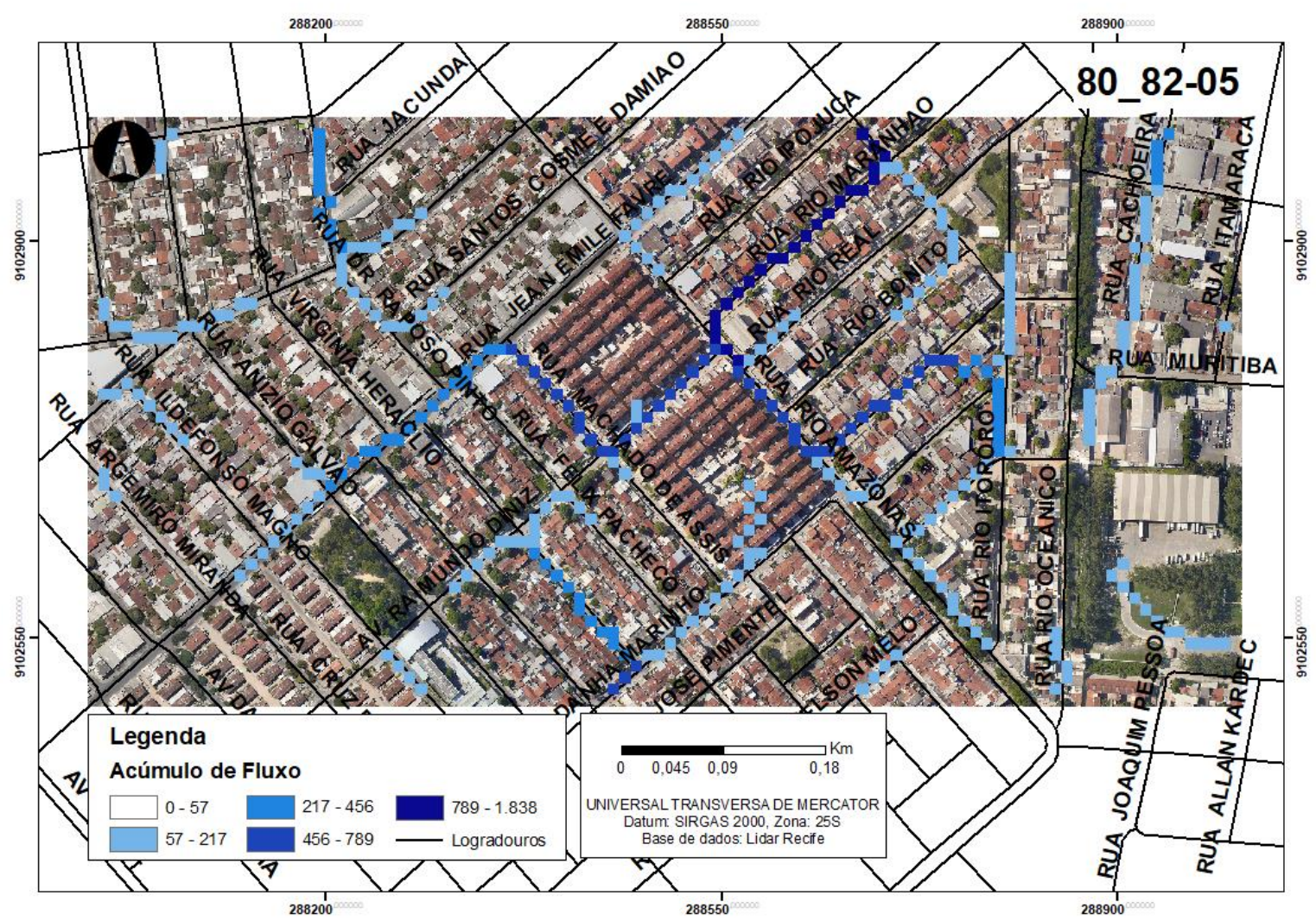

Figura 14: Acúmulo de fluxo da quadrícula de amostragem 80_82-05, Região político-administrativa 06.

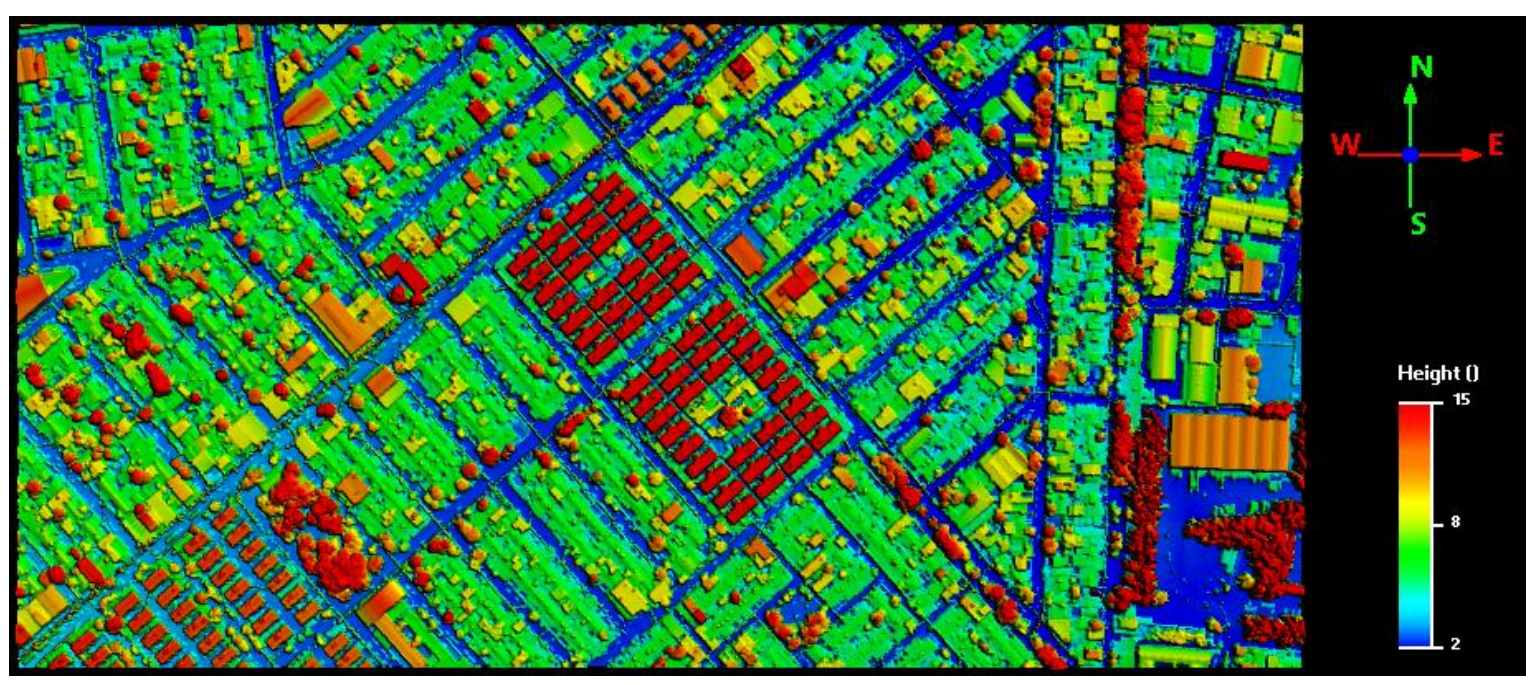

Figura 15: MDE da quadrícula de amostragem 80_82-05. 
A quadrícula 90_01-05 está localizada na zona sul de Recife, no bairro de Boa Viagem, que faz parte da RPA 06, Figuras 16 e 17. A área que é representada por essa quadrícula possui aproximadamente 25 ruas que abrigam uma enorme diversidade de construções, que vão de edifícios residenciais à shopping center, devido ao seu elevado índice de urbanização é possível notarmos uma certa homogeneização espacial.

O espaço representado pela quadrícula em questão possui uma alta importância para a cidade do Recife, se tratando de uma das principais zonas de influência do capital, ela possui um alto índice de ocupação e não apresenta áreas verdes em quantidades significantes, fazendo com que praticamente toda a área da quadrícula seja impermeabilizada. Essa impermeabilização impede que a maior parte da água que é precipitada durante os eventos pluviométricos consiga se infiltrar no solo e passa a escoar pelo sistema de drenagem da cidade, e devido a ineficiência do sistema de drenagem, acaba fazendo com que a população que habita naquele espaço tenha que vivenciar recorrentes enchentes urbanas. Esse tipo de enchente seria agravado pelo processo de urbanização. Segundo Tucci (2008) o desenvolvimento urbano pode também produzir obstruções ao escoamento, como aterros, pontes, drenagens inadequadas, obstruções ao escoamento junto a condutos e assoreamento.

$\mathrm{Na}$ área representada pela figura 8, é possível identificarmos as áreas mais afetadas, são elas a Rua Ribeiro de Brito, Av. Professor João Medeiros, Av. Fernando Simões Barros, Rua Bruno Veloso, Av. Domingos Ferreira, Av. Conselheiro Aguiar e a Rua José Trajano. As principais causas desses alagamentos podem ser atribuídas ao elevado índice de construções e a alta taxa de impermeabilização do solo, além da ineficiência existente nas ferramentas do sistema de drenagem do Recife. Um exemplo dessa ineficiência pode ser visto na quadrícula, entre as avenidas Professor João Medeiros e Fernando Simões Barros onde existe um canal, uma das ferramentas do sistema de macrodrenagem, que é um dos pontos mais sensíveis em relação a enchentes na quadrícula e que é agravado durante a ocorrência de eventos pluviométricos extremos.
Um outro ponto que merece destaque em relação a abundância de acúmulo superficial é a Av. Domingos Ferreira, porém as causas dos alagamentos nessa região ocorrem devido ao fator relevo, isso acontece porque a quadrícula está posicionada em uma área que por estar próxima ao litoral possui um relevo mais plano, agregado a esse posicionamento temos também o fato da avenida está em uma das zonas mais rebaixadas da quadrícula e além disso podemos também notar a influência do atrito gerado pelas construções que estão nas áreas que possui uma elevação considerável em relação a avenida, esse atrito faz com que algumas das ruas funcionem como uma espécie de canal que têm a capacidade de transportar uma certa quantidade da água precipitada para essa zona de rebaixamento, e devido a incapacidade de infiltração gerada pela pavimentação das vias, essa água se acumula causando danos a população que reside e que não reside nessa área.

A quadrícula 80_94-05, cujo mapa de acúmulo de fluxo corresponde a Figura 18, possui relevo homogêneo e edificações de médio e baixo porte, a leitura do MDE, Figura 19, demonstra que as edificações correspondem aos pontos mais elevados do relevo, surtindo impacto sobre a propagação das ondas de inundação; a altimetria do terreno varia entre 3 e 57 metros. A leste a quadrícula aloca o parque dos manguezais e a oeste a Lagoa do Araçá, pontos de escoamento natural das águas pluviais advindas do escoamento superficial.

Diferente das demais quadrículas de amostragem da RPA 06 que não possuem artifícios naturais ao escoamento a quadrículas em questão possui, entretanto o modelo de acúmulo de fluxo (Figura 18) ainda apresenta susceptibilidade a alagamentos em vários pontos, o que pode ser atribuir a ação das edificações sobre o escoamento com bloqueio de fluxo e perda da infiltração, além da diminuição da superfície de inundação expondo os pontos próximos aos corpos hídricos a variação da maré como é o caso das Avenidas José Ferreira Lins e Sul Governador Cid Sampaio. 


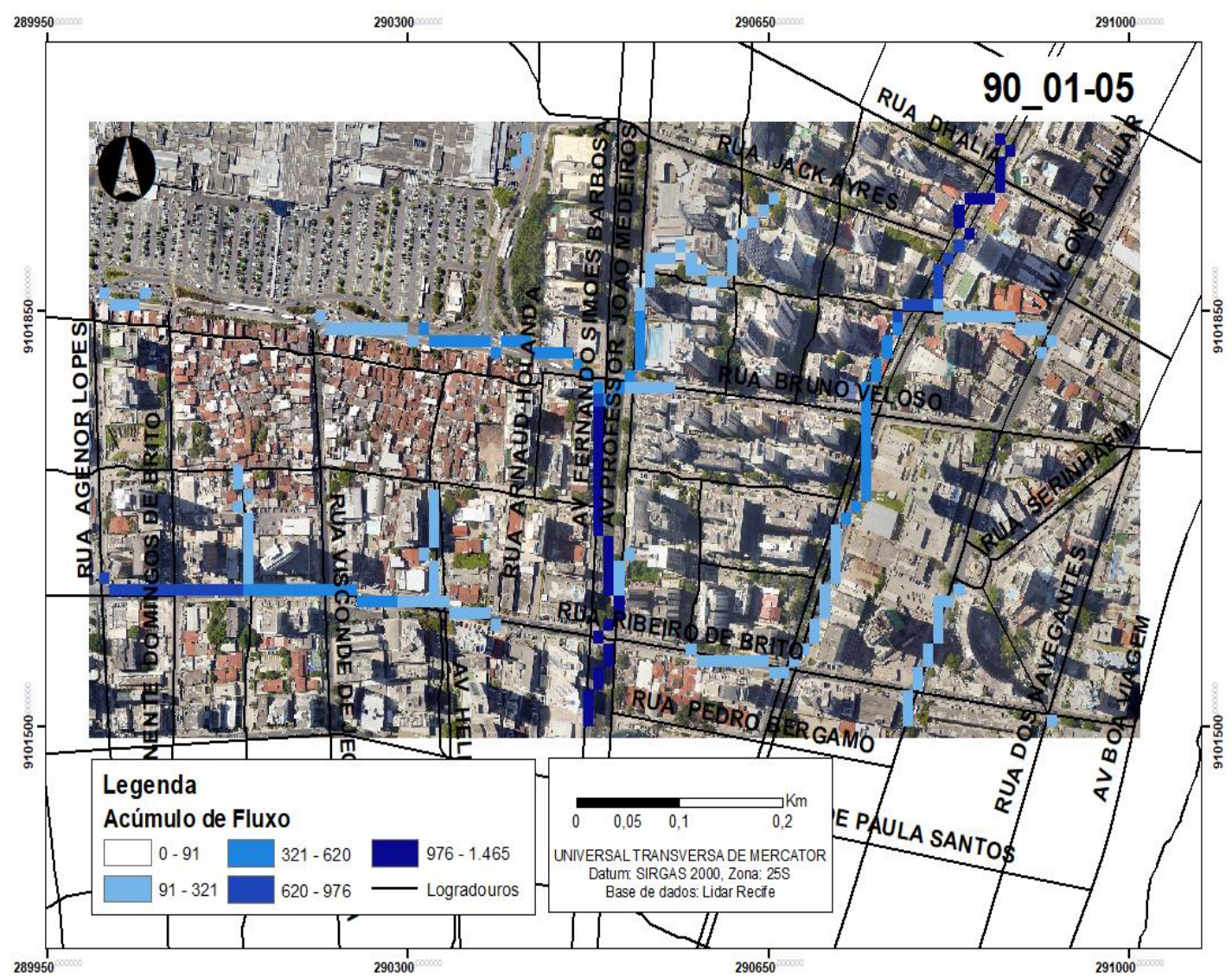

Figura 16: Acúmulo de fluxo da quadrícula de amostragem 90_01-05, Região político-administrativa 06.

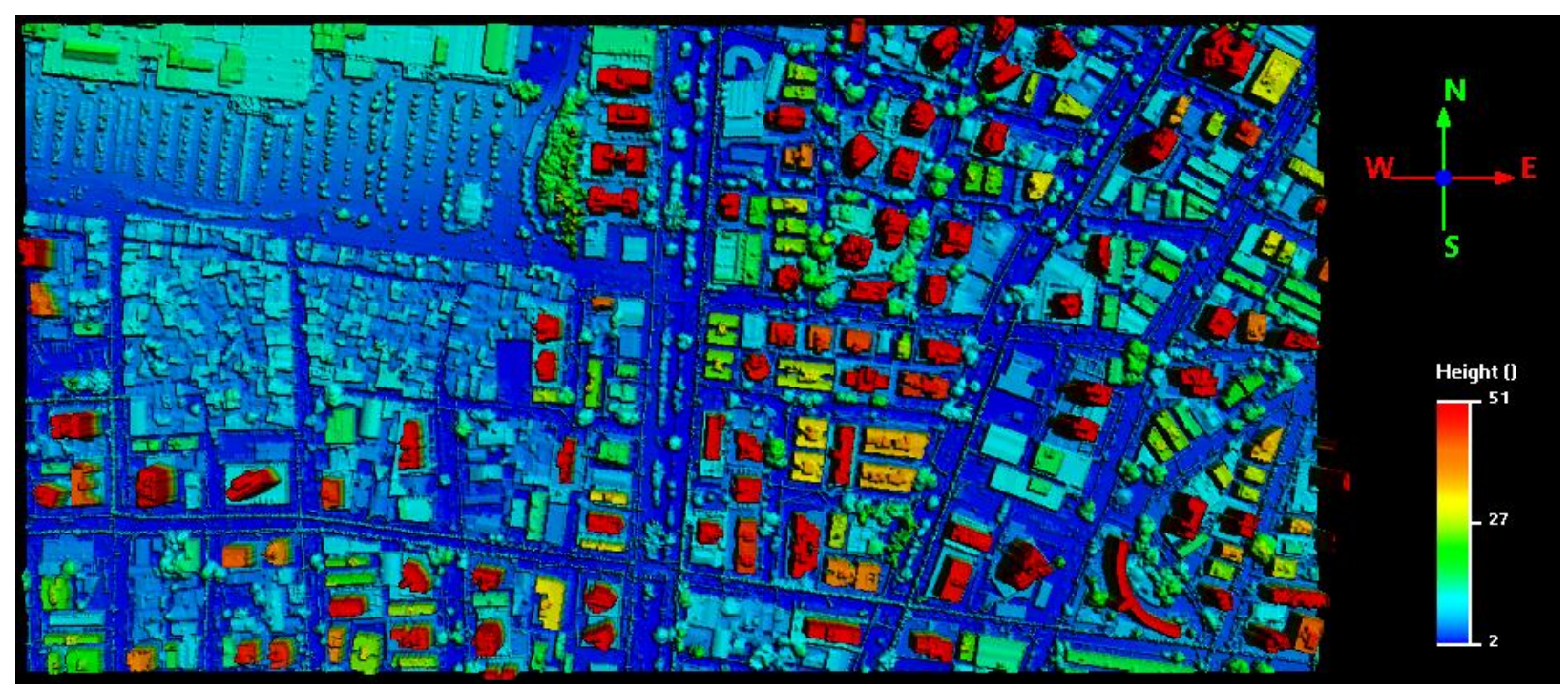

Figura 17: MDE da quadrícula de amostragem 90_01-05.

Os pontos mais sensíveis a alagamentos estão concentrados no centro da quadrícula sendo eles as ruas: Arquiteto Luiz Nunes, Avenida Mascarenhas de Morais, Avenida General Antônio de Góes Monteiro, Rua Deão Faria e Rua Juvina
Francisca de oliveira. É perceptível o comportamento de canal que as ruas demonstram, conduzindo fluxos de menor intensidade a áreas suscetíveis. Se pressupor a área de drenagem de uma bacia hidrográfica é possível atribuir

Lima; A. S., Bandim; C. G. A., Soares; G. A. S., Barros; J. P. F. G., Galvíncio, J. D. 
hierarquia de canais as ruas de menor impacto dos alagamentos as ruas de maior impacto, como exemplo a rua Zeferino Pinho e Avenida Mascarenhas de Morais que alimenta o acúmulode maior vazão ao final da Avenida General Antônio de Góes Monteiro no sul da quadrícula.

A quadrícula 90_25-05, cujo mapa de acúmulo de fluxo corresponde a Figura 20, é uma área sem grandes variações topográficas, isto é uma área basal próxima a linha de costa da praia de
Boa viagem. Os dados altimétricos fornecidos pelo MDE, Figura 21, indicam um relevo artificial constituído de prédios e construções de baixo porte características da região de Brasília Teimosa, uma das áreas de menor IDH na RPA 06. É observável que as avenidas e ruas possuemaltitudes uniformes entre 2 e 3 metros, de acordo com dados do Google Earth e observável pela coloração azul e verde que as representa no MDE.

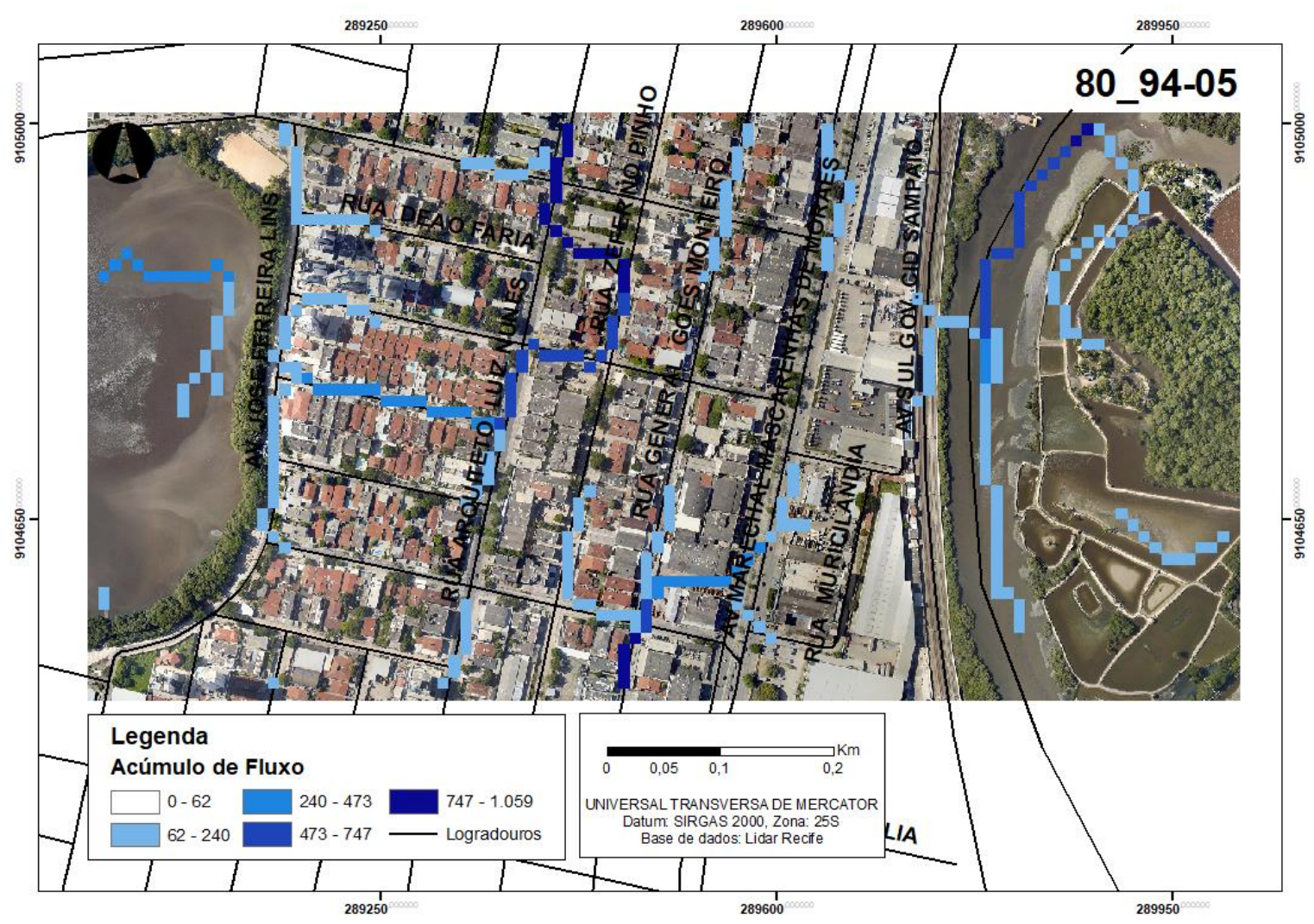

Figura 18: Acúmulo de fluxo da quadrícula de amostragem 80_94-05, Região político-administrativa 06.

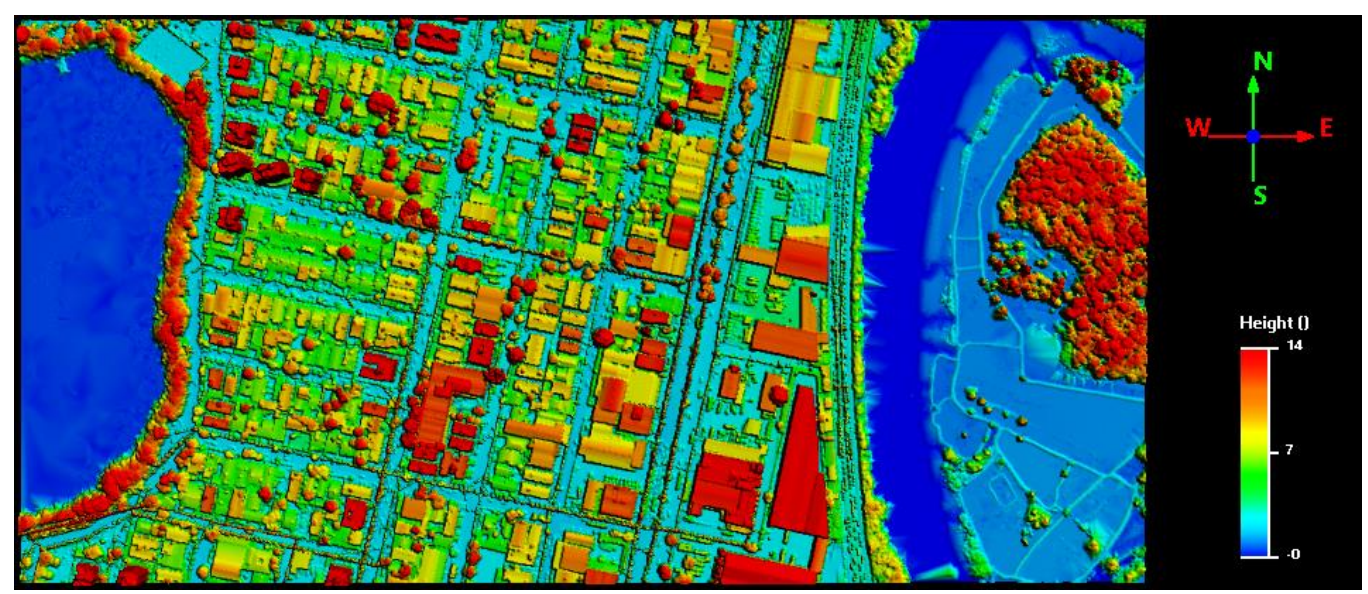

Figura 19: MDE da quadrícula de amostragem 80_94-05.

Lima; A. S., Bandim; C. G. A., Soares; G. A. S., Barros; J. P. F. G., Galvíncio, J. D. 
O modelo de acúmulo de fluxo evidencia alta suscetibilidade a inundações, o que decorre do atrito promovido pelas construções; o coeficiente de rugosidade da quadrícula impede o escoamento da água pluvial que tenderia a escoar a linha de costa e estuário do rio Capibaribe de acordo com o potencial gravitacional do escoamento, as alterações do ciclo natura finda inundações. A propagação das águas superficiais se comporta de formas diferentes na região leste e oeste da quadrícula devido ao bloqueio de fluxo promovido pelas edificações.

A região leste, que possui construções de pequeno porte, as ruas de maior suscetibilidade são Paru, Anequim, Poraquê, albacora, Albariana, Dagoberto Pires, Afrânio, Henrique Lins e Marechal Hermes, ambas sof rem com os menos dados hídricos de bloqueio de fluxo, o escoamento superficial que outrora tenderia a linha de costa sobre bloqueio pela grande quantidade de edificações irregulares somada a falta de planejamento urbano e déficit de saneamento.

Em contrapartida a região oeste possui edificações de grande porte com presença de prédios de até 100 metros de altitude, e de acordo com o modelo acúmulo de fluxo é acometida por índices mais elevadas de suscetibilidade a inundações. Sendo as áreas mais sensíveis a rua Das Oficinas e as famigeradas Avenidas Antônio de Góes e Herculano Bandeira, no caso particular os edifícios interceptam grande quantidade de água e bloqueiam o fluxo de escoamento conduzindo o fluxo as regiões mais rebaixadas com baixa capacidade de infiltração e redes de drenagem insuficientes.

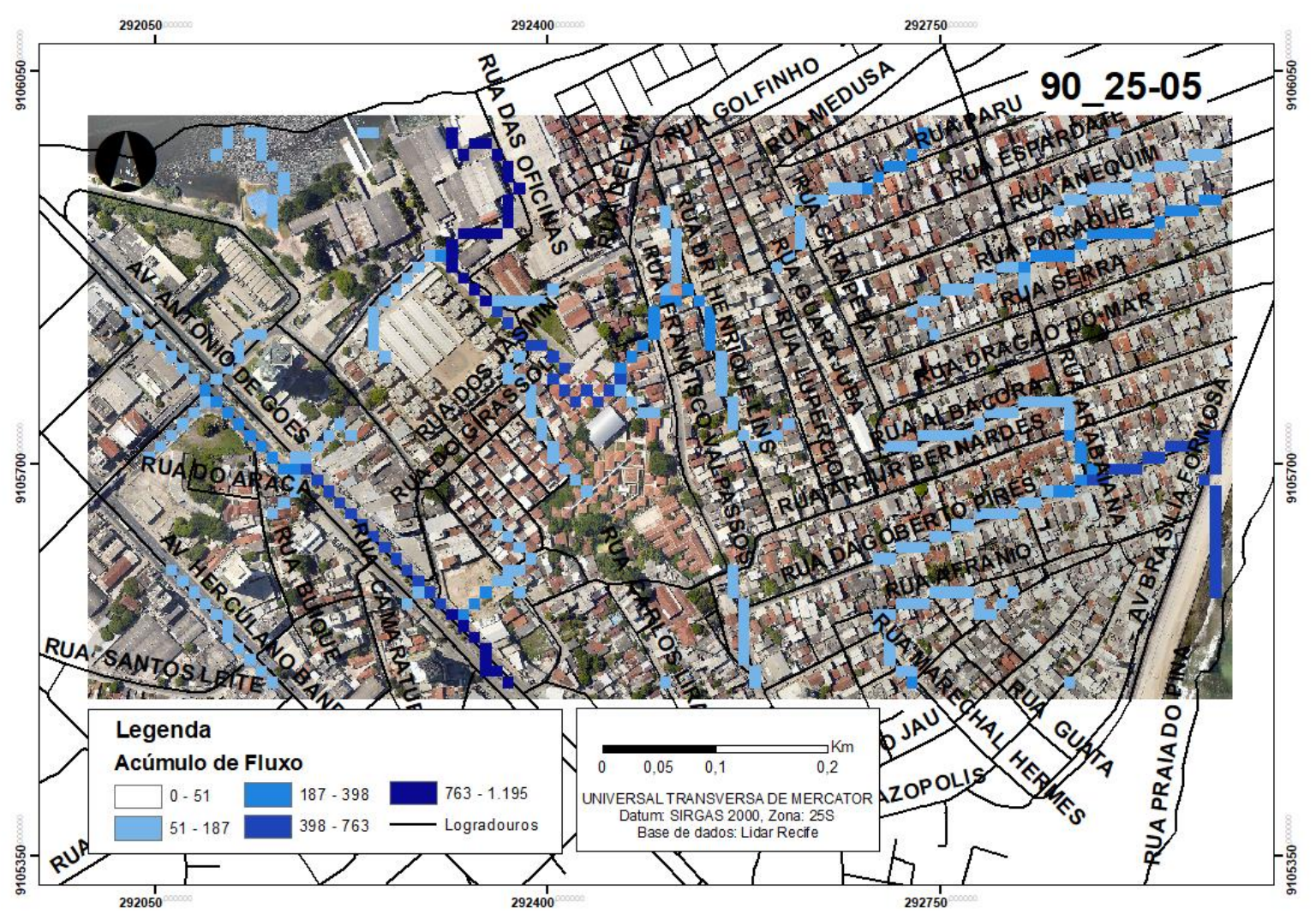

Figura 20: Modelo de acúmulo de fluxo da quadrícula de amostragem 90_25-05, Região políticoadministrativa 06. Fonte: autores. 


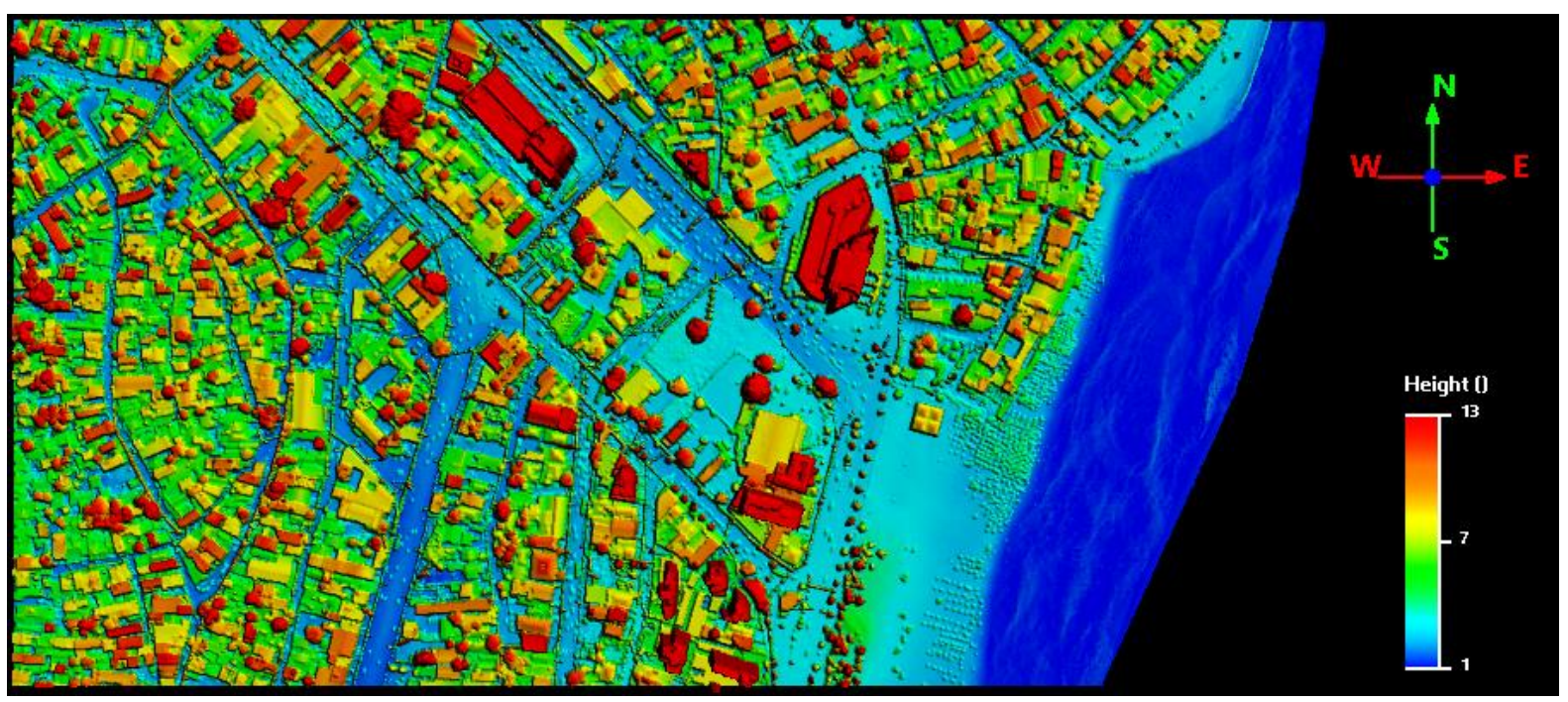

Figura 21: MDE da quadrícula de amostragem 90_25-05.

Na contramão do conceito ambientalista de conviver com a água, as cidades se desenvolvem desarmonicamente com o balanço hídrico. Essas interferências são resultado das dificuldades advindas do manejo das águas pluviais, visto que os problemas de drenagem ocorrem por ocasião de eventos hidrológicos de alta intensidade. Estes impactos dos alagamentos estão relacionados com mudanças no padrão de interceptação, transpiração, infiltração, percolação, entre outros; configurados, majoritariamente, pela impermeabilização do solo e desmatamento das áreas de várzea que dificultam a infiltração da água, aumentando o escoamento superficial e favorecendo outros fatores (SUDERHSA, 2002).

As características naturais da cidade do Recife, tais como a baixa altitude e as chuvas recorrentes, somadas à um mal desenvolvimento urbano, resultam em uma relação caótica entre o homem e o meio que o cerca, e finda no acontecimento de diversas catástrofes urbanas, como as inundações urbanas. Para o entendimento efetivo das problemáticas resultantes da relação estabelecida entre as sociedades e a natureza, é necessário observar as variáveis que propiciam a ocorrência dessas catástrofes, e compreender como as diferentes formas de uso ocupação, modificam as dinâmicas naturais e posteriormente causam transtornos à vida urbana.

Os dados processados das RPAs demonstram resultados relevantes a análise, visto que as regiões possuem taxa de urbanização e densidade demográfica diferentes, reverberando sobre resposta singulares em relação ao padrão de escoamento conforme o efeito do atrito das construções, isto é o coeficiente de rugosidade. As construções se apresentam como relevo artificial que conduz o fluxo e transforma as ruas em canais, o que sobre efeito da dinâmica hidroclimática e insuficiência dos sistemas de micro e macrodrenagem finda alagamentos signif icativos nas áreas de maior suscetibilidade. Nesse sentido Santos Junior et al (2013), discorre que os danos hidrológicos provocados pela urbanização, isto é, a impermeabilização do solo, diminuição da infiltração e retenção de água, aumenta a capacidade de escoamento superficial e acumulação das águas pluviais culminando em inundações urbanas, fato observável em maior parte das quadrículas de amostragem.

A análise do fluxo de água com base na topografia, interpretados a partir dos MDEs e processamento das quadrículas Lidar com a ferramenta Hydrology, indicaram que as mudanças no uso da terra e maior quantidade de edifícios altera o funcionamento dos processos que controlam o movimento natural da água, assim como produz linhas de fluxo em pontos densamente urbanizados. Visto que o escoamento responde as características físicas do relevo artificial, Brown (2007) no estudo sobre Canvey island considera que edifícios e construções são protagonistas na suscetibilidade a inundações urbanas por bloquearem o fluxo e exercerem atrito sobre o escoamento da água. Dada as características, vale ressaltar que a resolução do modelo digital de elevação usado, representa a interferência destas construções, os dados altimétricos fornecidos fundamentam os porquês da suscetibilidade a inundações.

As RPAs estudadas enfrentam severos problemas relacionados a alagamentos e enchentes, principalmente em períodos chuvosos. Além de inseridas nas bacias do rio Capibaribe e grupo de 
bacias litorâneas GL-1 e GL-2, o que possibilita, traçar um padrão nas ocorrências de alagamentos e enchentes. (SECTMA. CPRH. 2006). Os padrões hídricos das áreas em estudo, são um dos fatores determinantes para estabelecimento das relações entre o homem e o meio que o cerca.

Como consequência de estar localizada em área de clima tropical úmida e quente (As'. segundo a classificação de Köppen-Geiger), as chuvas estão sempre presentes na capital. Em meses de outono e inverno, são registrados os maiores índices, e são nessas épocas em que os fenómenos hidrológicos como alagamentos, enchentes e inundações ocorrem com maior regularidade, além de outros eventos, comoos movimentos de massa (Figura 5). A atuação do sistema atmosférico como Distúrbios Ondulatórios de Leste (DOLS) nesta época do ano, é um dos principais causadores desses fenômenos no meio urbano do Recife.

\section{Conclusão}

As áreas vegetadas em ambientes urbanos possuem importante papel no acúmuloe infiltração de água da chuva. Essas áreas são geralmente mais baixas quando comparadas aos edifícios e servem como ponto de exultório de água.

Os edifícios são barreiras artificiais que fazem a função de relevo fortemente ondulados que interferem no acúmulo de fluxo em áreas de relvo plano seja natural pu artificial. Quando artificial provoca problemas de inundações urbanas.

\section{Agradecimentos}

O segundo autor agradece à Fundação de Amparo a Ciência e Tecnologia de Pernambuco (FACEPE), pela concessão da bolsa de iniciação cientifica. $\mathrm{O}$ terceiro autor agradece ao Conselho Nacional de Desenvolvimento Científico e Tecnológico (CNPq), pela concessão da bolsa de iniciação científica. Dedicamos ainda, agradecimentos à Universidade Federal de Pernambuco (UFPE) e ao Laboratório de Sensoriamento Remoto e Geoprocessamento (SERGEO) do Departamento de Ciências Geográficas (DCG), por todo o suporte técnico e científico.

\section{Referências}

Bandim, C.G., Galvincio, J. D. 2021. Mapeamento das áreas de armazenamento de água em depressão, usando dados LIDAR: Estudo de caso avenida Caxangá. Revista Brasileira de Geografia Física, 14, 058-067. DOI: https://doi.org/10.26848/rbgf.v14.1.p058-067

Brown, J. D., Spencer, T., \& Moeller, I., 2007. Modeling storm surge flooding of an urban area with particular reference to modeling uncertainties: A case study of Canvey Island, United Kingdom. Water Resources Research [Online] 43.4 Disponível: doi.org/10.1029/2005WR004597.

DP. Diário de Pernambuco. Recife, uma cidade construída sobre aterros. Recife, 2016. Disponível: https://bityli.com/Yo2AY

Fewtrell, T. J., Duncan, A., Sampson, C. C., Neal, J. C., Bates, P. D., 2011. Benchmarking urban flood models of varying complexity and scale using high resolution terrestrial LiDAR data. Physics and Chemistry of the Earth, Parts A/B/C, 36(7-8), 281-291. Disponível: doi.org/10.1016/j.pce.2010.12.011.

França, L., Diaz, C., Reis, J., Costa, V., Galvíncio, J. 2019. Efeitos da precipitação na vazão da bacia hidrográfica do rio Pajeú-PE. Revista Brasileira de Geografia Física, 12(6), 23772391.

doi:https://doi.org/10.26848/rbgf.v12.6.p23772391

Gallegos, H. A., Schubert, J. E., \& Sanders, B. F., 2009. Two-dimensional, high-resolution modeling of urban dam-break flooding: A case study of Baldwin Hills, California. Advances in Water Resources [Online] 32(8). Disponível: doi.org/10.1016/j.advwatres.2009.05.008

Galvincio, J. D. Luz, G. G. 2021. Desenvolvimento de Modelo que Estima o Impacto do $\mathrm{CO} 2$ Atmosferico nas Precipitações do Estado de Pernambuco, utilizando ARIMA. Revista Brasileira de Geografia Física, 14, 1840-1851. Doi:https://doi.org/10.26848/rbgf.v14.4.p18401851

Galvíncio, J. 2019. Estimation of surface temperature with images obtained with drones. Journal of Hyperspectral Remote Sensing, 9(6), 397-406. doi:https://doi.org/10.29150/jhrs.v9.6.p397406

Galvíncio, J., \& Naue, C. 2020. Estimation of NDVI with visible images (RGB) obtained with drones.Journal of Hyperspectral Remote Sensing, 9(6), 407-420. doi:https://doi.org/10.29150/jhrs.v9.6.p407420

Girão, O., 2007. Análise de processos erosivos em encostas na zona sudoeste da cidade do Recife - Pernambuco. Tese (Doutorado). Rio de 
Janeiro, Universidade Federal do Rio de Janeiro (UFRJ).

Giacomini, A., 2018. $1^{\text {a }}$ Feira Do Conhecimento E Inovação (FCI). As aplicações no cotidiano das Leis de Newton e da Gravitação Universal. Disponível: https://bityli.com/sFKSI. Acesso: 13 jun. 2020.

Gonçalves, F. T., Nucci, J. C., 2017. Sistemas de drenagem sustentável (SUDS): propostas para a bacia do rio Juvevê, Curitiba-PR. Ra'e Ga - O Espaço Geográfico em Análise, 42, 192-209.

Hervouet, J. M., 2000. Um modelo de dam-break 2D de alta resolução usando paralelização. Processos hidrológicos, v. 14, n. 13, pág. 22112230. https://doi.org/10.1002/10991085(200009)14:13<2211::AIDHYP24>3.0.CO;2-8

IBGE. Instituto Brasileiro de Geografia e Estatística (IBGE). 2010.Censo Brasileiro de 2010. Rio de Janeiro.

Lima, C. E. S., Costa, V. S. O., Galvíncio, J. D., Silva, R. M., Santos, C. A. G., 2021. Assessment of automated evapotranspiration estimates obtained using the GP-SEBAL algorithm for dry forest vegetation (Caatinga) and agricultural areas in the Brazilian semiarid region. Agricultural Water Management, 250, 106863.

Marinho, R. R., Silva, E. C. M., 2016. Análise morfométrica de áreas afetadas por inundação urbana em Manaus (AM). Caminhos de Geografia (online) v. 17, n. 59, p. 162-176. Doi: https://doi.org/10.14393/RCG175910.

Miranda, R. Q., Galvíncio, J. D., Morais, Y. C. B.; Moura, M. S. B.; Jones, C. A. ; Srinivasan, R. 2018. Dry forest deforestation dynamics in Brazil?s Pontal basin. Revista Caatinga, 31, 385-395.

Mason, D. C., Horritt, M. S., Hunter, N. M., \& Bates, P. D., 2007. Use of fused airbome scanning laser altimetry and digital mapdatafor urban flood modelling. Hydrological Processes [Online] 21(11). Disponível: https://doi.org/10.1002/hyp.6343.

Morais, Y. C. B., Araújo, M. S. B., Moura, M. S. B.; Galvíncio, J. D., Miranda, R. Q. 2017. Análise do Sequestro de Carbono em Áreas de Caatinga do Semiárido Pernambucano. Revista Brasileira de Meteorologia, v. 32, p. 585-599, https://doi.org/10.1590/0102-7786324007

Moura, A. E. S. S. D., Correa, M. M., Silva, E. R. D., Ferreira, R. L. C., Figueiredo, A. D. C., Possas, J. M. C. 2009. Interceptação das chuvas em um fragmento de floresta da Mata Atlântica na Bacia do Prata, Recife, PE. Revista Árvore, 33(3), 461-469.

Novo, E. M. L. M., 2010. Sensoriamento Remoto: princípios e aplicações. $2^{\mathrm{a}}$ ed. Blucher, São Paulo.

Oliveira, G. C. S., Silva Junior, J. P., Nóbrega, R. S. Girão, O, 2011. Uma Abordagem da Geografia doClima Sobre os Eventos Ex tremos de Precipitação em Recife-PE. Revista Brasileira de Geografia Física, Recife - PE, v. 02, p. 238-251. Disponível: doi.org/10.26848/rbgf.v4i2.232707

Ozdemir, H., Sampson, C. C., Almeida, G. A., \& Bates, P. D., 2013. Evaluating scale and roughness effects in urban flood modelling using terrestrial LIDAR data. Hydrology and Earth System Sciences [Online] 17(10). Disponível: doi.org/10.5194/hess-17-40152013

Porto, R.; Zahed Filho, K.; Tucci, C. E. M.; Bindone, F., 2012. Drenagem Urbana. In: Tucci, C. E. M. (Org.). Hidrologia, ciência e aplicação. 4 ed. Porto Alegre: Editora da UFRGS/ABRH. Porto Alegre. 130 - 146.

Recife (município). Lei $\mathrm{N}^{\circ} 15.547 / 91$ de 19 de dezembro de 1991. Seção III, Da drenagem pluvial, Art.81.

Rodrigues, M. 1993. Geoprocessamento: um retrato atual. [Entrevista]. Fator Gis: a Revista do Geoprocessamento, 1(2), 20-23.

Sampson, C. C., Fewtrell, T. J., Duncan, A., Shaad, K., Horritt, M. S., \& Bates, P. D., 2012. Use of terrestrial laser scanning data to drive decimetric resolution urban inundation models. Advances in Water Resources [Online] 41. Disponível: doi.org/10.1016/j.advwatres.2012.02.010.

Santos júnio, V.J. Santos, C. O. 2013. A evolução da urbanização e os processos de produção de inundações urbanas. Estação Científica (UNIFAP), 3, 19-30.

Sectma. Secretaria de ciência, tecnologia e meio ambiente. CPRH. Agência Estadual de Meio Ambiente e Recursos Hídricos, 2006. O meio físico e biótico da área, in: Estudos ambientais do núcleo Metropolitano da Zona Costeira de Pernambuco. Recife.

Soares, G., Galvíncio, J. 2020. Uso do Lidar para avaliar os padrões hídricos de bacias em áreas urbanas: Caracterizaçãofisiográfica da bacia do Rio Beberibe, PE. Revista Brasileira de Geografia Física, 13, 3659-3674. Disponível: doi.org/10.26848/rbgf.v13.07.p3659-3674

Suderhsa. Superintendência de Desenvolvimento de Recursos Hídricos e Saneamento Ambiental, 
2002. Manual de drenagem urbana: Região metropolitana de Curitiba- Paraná.

Stamm, C., Staduto, J. A. R., Lima, J. F. D., \& Wadi, Y. M., 2013. A população urbana e a difusão das cidades de porte médio no Brasil. Interações (Campo Grande), 14, 251-265.

Tucci, C. E. M., 1997. Água Doce: Água no meio urbano. Rio Grande do Sul.

Tucci, C. E. M.; Bertoni, J. C., 2003. Inundações Urbanas na América do Sul. 1 ed. Porto Alegre:Associação Brasileira de Recursos Hídricos. Porto Alegre.

Tucci, C. E. M., 1993. Controle de Enchentes, in: Tucci, C. E. M. (org). Hidrologia: ciência e aplicação. ABRH, Porto Alegre, 621-658.
Tucci, C. E. (2003). Drenagem urbana. Ciência e cultura, 55(4), 36-37.

Tucci, C. E. M. (2008). Gestão integrada das águas urbanas. Revistade Gestão de Água da América Latina, 5, 71-81.

Tucci, C. E. M., 2004. Hidrologia: ciência e aplicação. 3. ed. Porto Alegre: ABRH. Porto Alegre.

Tucci, C. E. M., 2009. Hidrologia ciência e aplicação. Editora da UFRGS, Porto Alegre.

Tsubaki, R., \& Fujita, I., 2010. Unstructured grid generation using LiDAR data for urban flood inundation modelling. Hydrological Processes [Online] 24(11). Disponível: doi.org/10.1002/hyp.7608. 